\title{
LA CRISIS DE LAS ALIANZAS EN EUROPA (1895-1896)
}

por

\author{
CRISTÓBAL ROBLES MUÑOZ \\ Instituto de Historia, CSIC
}

RESUMEN: La entente franco-rusa y la Triple Alianzas deberian ser garantía de paz. Ambas estaban a favor del statu quo. Italia mantenía buenas relaciones con el Reino Unido y con España, con el visto bueno de sus dos aliados, porque así se debilitaba a Francia. Esta podría quedarse aislada si el gobierno de Salisbury hubiera tenido que vincularse con la Triple Alianza para resistir las pretensiones francesas sobre Egipto. Se produciría un reagrupamiento de las potencias europeas. Habia otras combinaciones. Una de ellas, la unión del Reino Unido con Rusia frente a Francia. Se atisbaba la de esta con el Reino Unido mediante un convenio sobre las zonas en litigio en sus colonias. Sucedia esto cuando babía una guerra contra España en Cuba y se temía una injerencia de Estados Unidos en ella.

PAlabras Clave: Triple Alianza. Diplomacia. Siglo XIX.

ABSTRACT: The Franco-Russian entente of the early 1890s and the Triple Alliance (Germany, Austria-Hungary, Italy) should have guaranteed peace. Both favoured the status quo. Italy retained a good relationship with the United Kingdom and with Spain, who looked positively upon this as a means of debilitating France. The French would have become isolated if Lord Salisbury's government had finally chosen to join the Triple Alliance in order to resist French pretensions in Egypt, since this would have brought a regrouping of the European powers. There were other possible combinations, too, including an alliance between the United Kingdom and Russia, against France, or an Anglo-French rapprochement through an agreement about disputed colonial territories. This occurred during the Cuban war of independence, as a result of apprehensions about the interference of the United States.

KEY WORDS: Triple Alliance. Diplomacy. Nineteenth century.

España creyó que sus intereses en Marruecos quedaban mejor defendidos si todo seguía igual. Esa posición era ya una tradición política en 1880 , cuando se celebró la Conferencia de Madrid. Si se aproximó a Italia e Inglaterra fue para 
impedir que Francia modificase la situación. Creyó que tener «las manos libres» era la fórmula mejor para sumar apoyos en caso necesario y no restar nada a los recursos que necesitaba en Cuba.

El desinterés de Austria-Hungría y del Reino Unido, aliados de Italia desde 1887, afectó al equilibrio en el Mediterráneo. En Roma creían que, con esa conducta, se consolidaba el predominio francés en el Mediterráneo occidental, y el dominio ruso, en el oriental. Esa política agresiva quebró la expectativa de paz creada por la entente franco-rusa.

Iniciada en febrero de 1895 la guerra en Cuba y existiendo problemas en Filipinas, la situación será uno de esos costes de la guerra colonial no olvidados $^{1}$. Se convirtió en acusación por la derrota y serviría para explicar los problemas nacionales.

\section{LAS MANIOBRAS DE FRANCIA}

El 8 de mayo el gobierno de Francesco Crispi convocó elecciones. Se celebraron el 26 de ese mes. Tras varios meses de suspensión de las sesiones, el 10

SIGLAS:

AAE CP: Archive du Ministères des Affaires Extérieures, Correspondence Politique, París, volumen y páginas

AAE NS Espagne: Archive du Ministères des Affaires Extérieures, Nouvelle série, París, volumen y páginas

AGP: Archivo General de Palacio, Madrid, cajón y expediente

AMAE H: Archivo del Ministerio de Asuntos Exteriores, Madrid, sección histórica, legajo ASD AP A: Archivio Storico Diplomatico, Affari politici, serie A, Roma, busta e fascicolo

ASD SP P: Archivio Storico Diplomatico, serie politica, Roma, pacco

ASD CV: Archivio Storico Diplomatico, cassette verdi, nombre que recibe el Archivio Riservato del Segretario Generale e del Gabinetto, busta, fascicolo e numero, Roma

ASV SS: Archivio Segreto Vaticano, Segreteri di Stato, rubrica, anno, fascicolo e foglio.

DDF: Documents Diplomatiques Français

DDI: Documenti Diplomatiici Italiani

ASD DDS: Documenti Diplomatici a Stampa, en el ASD, textos impresos bajo la rubrica «confidenziale».

DS/C. Diario de las Sesiones de las Cortes. Congreso de los Diputados

L.p.: Lettre particulière y lettera particolare.

MCRR: Museo Centrale del Risorgimento, Roma, caja, fascículo y documento.

R.: Reservado, Riservato, Reservé.

s.n.: $\quad$ sin número.

t.c. telegrama cifrado.

Esta expresión alude al título de un excelente trabajo de SÁNCHez ABADía, Silvia: «Olvidos de una guerra: el coste humano y económico de la independencia (Cuba-España, 1895-1898)», en Revista de Indias (Madrid) 33 (2001), pp. 113-140.

Hispania, LXV/2, núm. 220 (2005) 643-682 
de junio de 1895, el rey Umberto I abrió la nueva legislatura en Italia ${ }^{2}$ En su discurso advertía que la pertenencia a la Triple Alianza y la amistad de Italia con el Reino Unido ${ }^{3}$ no autorizaban a las otras potencias europeas a sospechar de un gobierno, presidido por alguien considerado hostil a Francia ${ }^{4}$. Con ella, estaba pendiente la negociación comercial.

En una entrevista con Gabriel Hanotaux, ministro de Asuntos Exteriores francés, el embajador Giuseppe Tornielli-Brusati di Vergano comentó un artículo distribuido por la agencia Havas, en el cual se decía que la pertenencia de Italia a la Triple Alianza era un obstáculo para llegar a un acuerdo comercial. El hecho de que ese texto procediera de un órgano que se creía vinculado a la embajada de Francia en Roma le daba un carácter casi oficioso. Hanotaux lo calificó como habladurías de la prensa. Bastaba mirar el acuerdo reciente comercial franco-suizo. La comisión parlamentaria no impuso límites para extender su contenido a otros países. El gobierno no consentiría que la oposición recortara su libertad de acción 5 .

Al sur del Mediterráneo, en Marruecos, continuaba la rivalidad entre las potencias europeas. Semanas antes, a comienzos de febrero de 1895, El Imparcial informó del malestar causado por la prolongada estancia en Fez del ministro inglés, Ernest Satow, y del intérprete de la legación italiana. El diario de Madrid quería apresurar su regreso para que, cuando llegaran a Fez los ministros de Francia y España, Mombal y Emilio de Ojeda, tuvieran campo libre para plantear sus demandas.

Esta campaña, tachada por el funcionario italiano de fundarse en noticias falsas, buscaba obstaculizar las relaciones de España con Inglaterra e Italia, destacando el buen momento por el que pasaban las que existían con Francia ${ }^{6}$.

La prensa española silenció la noticia del avance de las tropas francesas en el Tuat. Parecía que Inglaterra, de acuerdo ahora con Rusia, dejaba manos libres a Francia en Marruecos y Madagascar a cambio de que aceptara sus proyectos en Egipto?.

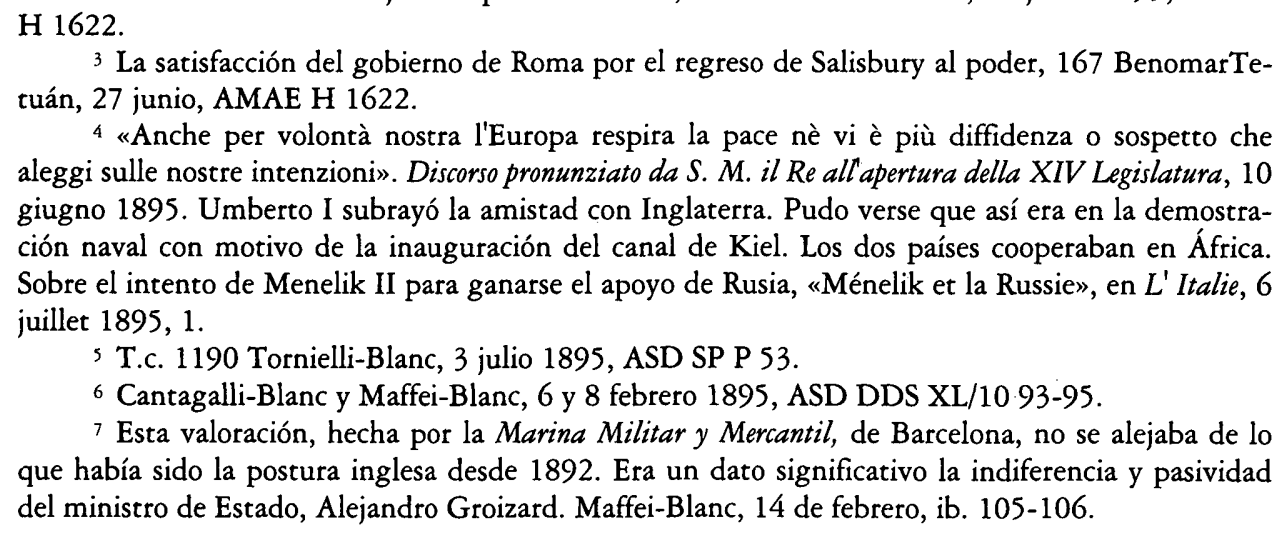

3 La satisfacción del gobierno de Roma por el regreso de Salisbury al poder, 167 BenomarTetuán, 27 junio, AMAE H 1622.

4 "Anche per volontà nostra l'Europa respira la pace nè vi è più diffidenza o sospetto che aleggi sulle nostre intenzioni». Discorso pronunziato da S. M. il Re all apertura della XIV Legislatura, 10 giugno 1895. Umberto I subrayó la amistad con Inglaterra. Pudo verse que así era en la demostración naval con motivo de la inauguración del canal de Kiel. Los dos países cooperaban en África. Sobre el intento de Menelik II para ganarse el apoyo de Rusia, "Ménelik et la Russie», en L' Italie, 6 juillet $1895,1$.

5 T.c. 1190 Tornielli-Blanc, 3 julio 1895, ASD SP P 53.

6 Cantagalli-Blanc y Maffei-Blanc, 6 y 8 febrero 1895, ASD DDS XL/10 93-95.

7 Esta valoración, hecha por la Marina Militar y Mercantil, de Barcelona, no se alejaba de lo que había sido la postura inglesa desde 1892. Era un dato significativo la indiferencia y pasividad del ministro de Estado, Alejandro Groizard. Maffei-Blanc, 14 de febrero, ib. 105-106.

${ }^{2}$ Un balance del embajador español en Roma, 165 Benomar-Tetuán, 26 junio 1895, AMAE 
Quienes conocían la historia de Marruecos admitían que la sucesión de Muley El Hassan fue más pacífica que en casos anteriores. Por eso la decisión del ministro de Alemania en Tánger, el conde Christian Tattenbach, de que un destacamento de su país desembarcara en Safi en la costa atlántica, fue un error, pues permitía que otros países hicieran lo mismo, poniendo así en cuestión el statu quo.

La acción alemana era inoportuna después que el gobierno marroquí prometiera hacer justicia por el asesinato de Rockstroh, un ciudadano alemán ${ }^{8}$. Para Tattenbach las exigencias de su gobierno eran innegociables. Se endurecerían cuanto más tiempo se tardase en satisfacerlas. Ignoraba la situación interna de Marruecos y la oposición de los intransigentes a los ministros del nuevo Sultán?.

El gran visir calificó esa conducta como «imprudente y agresiva». Esperaba Satow que Italia ejerciese sus buenos oficios y desde Berlín enviaran instrucciones rectificando la actuación de Tattenbach ${ }^{10}$. Su energía respondía al modo como trataban los ministros marroquíes los asuntos importantes que afectaban a las otras naciones ${ }^{11}$.

El 10 de julio entraron en el puerto de Tánger la fragata «Storch» y el crucero "Hagen", con unos 700 hombres y 23 cañones. Faltaba aún otra nave ${ }^{12}$. El gobierno alemán encargó a su embajador en Madrid que explicara esta decisión. Radowitz estuvo con el duque de Tetuán. El ministro de Estado no dudaba de que Alemania pensara modificar el statu quo. Confiaba que no se adoptara una posición agresiva, que traspasara lo que exigía la seguridad de los ciudadanos alemanes en Marruecos. ¿Se había escogido ese escenario para forzar decisiones en Madrid? El ministro de Estado estaba seguro de que el desembarco era una

${ }^{8}$ El gobierno marroquí probó su voluntad de hacer justicia cuando ejecutó al autor del asesinato de Newmann, también ciudadano alemán. Según el ministro de Berlín en Tánger, el último incidente era más grave. La conducta de los caídes ofendía a un nación amiga, como Alemania.

9 El resultado final supondría un deterioro de las relaciones mutuas y reduciría la influencia alemana en Marruecos. Mombal, que se acercaba esos días a Fez, utilizaría la crisis en beneficio de Francia. D'Aspremont-Blanc, 15 mayo 1895, ASD DDS XLI10 229-230. Disgustó a E. Satow el cambio de conducta de su colega alemán, d'Aspremont-Blanc, 19 de mayo, ib. 235-236.

10 Gianatelli Gentile-C. d'Aspremont, 16 mayo, anexo a d'Aspremont-Blanc, 21 mayo, ib. 237-238. Más datos sobre el incidente, d'Aspremont-Blanc, 23 y 31 mayo, ib. 243-244 y 247.

249. Parece que se pidió lo mismo a White y Ojeda. D'Aspremont-Blanc, 12 junio, ib. 279. White transmitió a Guillermo II y al príncipe Hohenlohe la queja del gobierno de Fez. La reacción de Tattenbach fue reiterar el ultimátum presentado. D'Aspremont-Blanc, 16 junio, ib. 285-286.

$"$ Gianatelli Gentile, siguiendo esa norma, trabajó para que el incidente se resolviera amistosamente, pero no podía ocultar la decepción el Sultán. Las potencias amigas le daban consejos, pero le negaban su apoyo. D'Aspremont-Blanc, 21 de junio, ib. 295-297. Cuando el embajador Radowitz explicó a su colega francés la decisión de su gobierno, dijo que el Sultán, en una carta a Guillermo II, había recusado a Tattenbach, pese a que tenía el apoyo de su gobierno. 94 Reverseaux-Hanotaux, 18 de julio, AAE CP Espagne 927111.

${ }_{12}$ D'Aspremonnt-Blanc, 10 julio, ASD DDS XL/10 313. Francia no se oponía a que los alemanes ocuparan algún punto de la costa de Marruecos hasta obtener satisfacción a sus demandas. C. Calvi-Blanc, Berlín, 24 julio, ib. 345.

Hispania, LXV/2, núm. 220 (2005) 643-682 
maniobra para que el gobierno español «par crainte de complications extérieures» renovara el tratado comercial con Alemania. Si eso fue así, no lo consiguió Alemania. Cánovas no daría un paso sin sondear antes a Francia. Las circunstancias en el Mediterráneo habían variado radicalmente tras la visita de la flota rusa a Toulon y el conocimiento de que existía la entente franco-rusa ${ }^{13}$.

Inglaterra relevó a Satow. Su sucesor, Arthur Nicholson, era cónsul general en Sofía. Estaba en la carrera diplomática desde 1870. Conocía bien. los asuntos de Oriente. Acompañó a Lord Frederick Temple Hamilton Dufferin and Ava, embajador en París, durante su viaje a Egipto en 1882-1883. Conocía las lenguas orientales, como el persa y el turco y quizás el árabe ${ }^{14}$.

Se recelaba de la existencia de un acuerdo entre Francia y Marruecos por el que éste se obligaba a no tratar nada con una potencia extranjera sin consultar antes al gobierno de la República y éste se comprometía a defender a Marruecos de cualquier agresión extranjera. Era un protectorado que preocupaba seriamente a Herbert $\mathrm{E}$. White.

Aunque había que recibir con cautela la noticia, la crisis interna en Marruecos, con revueltas en el Sur, la desorganización administrativa y numerosas demandas pendientes con las naciones europeas, podrían haber inducido a Mombel, entonces en Fez, a ofrecer esa protección. Tattenbach no lo creyó. Salisbury preguntó a Ferrero, el embajador de Italia en Londres, si su gobierno conocía del asunto ${ }^{15}$.

La oferta francesa fue rechazada, pero algunos estaban dispuestos a aceptarla, temerosos de que la anarquía destruyese la nación y Marruecos perdiese su independencia ${ }^{16}$.

Acudieron ese verano a Fez mandatarios del representante del Sultán en Figuit para protestar por el proyecto francés de construir el ferrocarril pasando por su territorio. Era un golpe de efecto montado por el gran visir. Mombel se limitaría a lamentar el incidente y las cosas seguirían como hasta ese momento.

${ }^{13}$ Henry Drummond Wolff, embajador inglés en Madrid, dijo a su colega francés que esta nueva situación exigía "veiller de près pour y maintenir la paix, car tout le monde veut y jouer un rôle». "Celui de l'Angleterre n'y est certainement plus aussi facile que jadis», replicó $H$. de Reverseaux. 89 Reverseaux-Hanotaux, 9 julio, AAE CP Espagne 927 99-100. Meses más tarde, el cónsul de Francia en Mogador comentó que favorecía a su país que nada cambiara en Marruecos, pues la apertura al comercio y a las empresas extranjeras incrementaría la hegemonía que ya tenían los ingleses. L.p. M. L. Leril-Léon Bourgeois, 14 abril 1896, AAE NS Maroc 180.

${ }^{14}$ Satow dejaba alto el prestigio de su país en Marruecos. D'Aspremont-Blanc; 1 julio, ASD DDS XL/10 305 .

15 D'Aspremont-Blanc, 23 julio, y A. Ferrero-Blanc, 26 julio, ib. 353 y 359.

16 D'Aspremont-Blanc, 6 agosto. Las dificultades de Mombel en Fez para conseguir sus objetivos, D'Aspremont-Blanc, 8 agosto, ib. 383 y 395. Mombel, a su regreso, se mostró satisfecho del resultado de su misión, D'Aspremont-Blanc, 15 agosto. El comentario de duque de Tetuán a Maffei y a Drummond Wolff sobre los logros de Mombel y la información del embajador inglés sobre la oferta francesa al gobierno marroquí, Maffei-Blanc, 22 septiembre, ib. 409 y 463. 
Los franceses proseguirían su obra. En París no estaban dispuestos a discutir sobre el Tuat. Se negaban a hacerlo desde hacía varios años ${ }^{17}$.

A principios de agosto de 1895 el embajador Jacques-Marie Fernand de Reverseaux de Rouvray desmintió la noticia de que España e Inglaterra habían convenido hacer una demostración naval en Tánger ${ }^{18}$. Cánovas permanecía en «sa ferme volonté de maintenir le statu quo et de marcher dans ce but en plein accord avec la France et l'Angleterre, également intéressées à cette politique» ${ }^{19}$.

Una serie de incidentes en Uasán podría proporcionar a Francia la ocasión para intervenir en Marruecos ${ }^{20}$. En noviembre de 1895 , Le Petit Journal calificó como «maniobra anexionista» un rumor de que el Sultán de Marruecos habría enviado una expedición al Tuat. Había muerto el teniente Bérard en una operación de reconocimiento en las cercanías de Tombuctú.

Podría desatarse el fanatismo musulmán, comprometer los resultados obtenidos en la región de Guerara y quedar amenazada la tranquilidad en la frontera con Argelia. Alentado por algunas potencias europeas, el Sultán quería transformar en soberanía la influencia religiosa que ejercía en el Tuat, una región de indudable valor estratégico, comercial y político, del que Francia tenía derecho a beneficiarse. Para eso urgía prevenir todo intento de Marruecos de ejercer en aquella zona un acto de soberanía. «Les droits de la France sur le Touat sont incontestables» y estaban recogidos en el artículo VI del tratado del 18 de marzo de 1845. Se quería cortar a Francia una ruta hacia el Atlántico. El Tuat era «une affaire purement algérienne» ${ }^{21}$.

Estaba bien informado el redactor de Le Petit Journal. Días antes, Mohamed Torres estuvo con el ministro inglés en Tánger. Le comunicó la protesta de Francia por los actos de soberanía del Sultán en el Tuat. Por orden de Sid Ahmed Ben Mussa, solicitó a Arthur Nicholson su opinión. La nota no contenía intimidación alguna. Sin discutir sobre ese punto, el proyecto de respuesta afirmaba que la región de Tuat, Guerara y Tidikelt pertenecía desde hacía mucho tiempo a Marruecos. Nicholson creía que debía informarse de la nota a los representantes de las demás potencias, pero no estaba autorizado Torres para hacerlo.

17 D'Aspremont-Blanc, 28 julio. El representante francés en Marruecos obtuvo la destitución de Sid Feddul Garrit, responsable de los Asuntos Exteriores. D'Aspremont-Blanc, 1 agosto, ASD DDS XI-110 371 y 381 .

18 «Il n' y a aucune correlation entre la présence des escadres anglaises et espagnoles dans les eaux du Maroc et aucune entente entre les deux gouvernements». T. c. Reverseaux-Hanotaux, 10 agosto, AAE CP 927146.

19102 y 104 Reverseaux-Hanotaux, 10 y 12 agosto, ib. $147-148$ y $153-154$.

${ }^{20}$ Aunque esa amenaza fue desmentida por Mohamed Torres, el encargado de negocios italiano creía que había existido. D'Aspremont-Blanc, 9 septiembre, ASD DDS XL/10 451. Sobre los desórdenes en Tánger, D'Aspremont-Blanc, 15 septiembre, ib. 457-458. Mohamed Torres comentó la inestabilidad interna, la debilidad del Sultán y la incompetencia de sus consejeros. D'AspremontBlanc, 4 septiembre, ib. 443.

${ }^{21}$ Este artículo fue enviado como anexo a Tornielli-Blanc, 22 noviembre, ASD DDS XL/10 507. 
Pese a su intimidación, no consiguió Mombel durante su visita a Fez que Marruecos admitiera que carecía de derechos en la región. Todos los indicios apuntaban a que ese fracaso había decidido al gobierno de París a actuar con decisión y energía ${ }^{22}$.

El ministro de Francia, en una Nota, se quejó de que el gobierno marroquí enviara gobernadores al Tuat. Eran actos de soberanía en una zona, considerada parte de Argelia. La protesta no contenía amenaza alguna y recordaba que, meses antes, había pedido al Sultán una renuncia expresa sobre el Tuat ${ }^{23}$.

Para saber la posición del gobierno ingles, Mohamed Torres habló con Arthur Nicholson. Obedeciendo las instrucciones de Salisbury, se mantuvo reservado. Dos semanas después Mohamed Torres se dirigió al ministro de Italia en Tánger ${ }^{24}$.

Aplazada una decisión debido a que las tribus se habían preparado para la defensa, pero convencida la opinión francesa de sus derechos, todos daban por conquistado el Tuat. Lo necesitaba Francia si quería abrir una vía al Sahara y al Senegal desde Argelia ${ }^{25}$

\section{TODOS POR LA PAZ EN EUROPA}

Como hemos visto, Henry Drummond Wolff subrayó la importancia de la entente franco-rusa. En París desearon destacar su carácter pacífico. No iba contra Alemania y su fin era defensivo. Coincidía con la Triple Alianza. «Une combination et l'autre sont faites pour la paix non pour la guerre; pour maintenir le statu quo et non pour préparer le changement!». Todo seguiría igual en Europa. Rusia no había aceptado mención alguna a la recuperación de Alsacia y Lorena y Francia había rechazado cualquier compromiso de entrar en guerra con Alemania. Esta era la tesis oficial ${ }^{26}$.

La nueva orientación internacional de Italia, recogida en el ya citado discurso de apertura de la Legislatura, reforzando la voluntad de acuerdo con el Reino

${ }^{22}$ Cantagalli-Blanc, 30 noviembre. Salisbury aprobó la actitud reservada de Nicholson. Cantagalli-Blanc, 13 diciembre, ib. 511-512 y 531.

${ }^{23}$ R. 892/254 Cantagalli-Blanc, 30 noviembre, ASD AP P 201.

${ }^{24}$ R. 930/376 R. Cantagalli-Blanc, 13 diciembre, ASD AP P 201.

2s Comentario de Villebois de Mareuil, coronel del primer regimiento de la legión extranjera. G. Malmusi-Blanc, 17 enero 1896, ASD DDS XL 11 11. Era la tesis publicada en un artículo del Journal des Débats, inspirado o redactado por Linares o por La Martinière. G. Malmusi-Blanc, 8 febrero, ib. 17. Sobre la relación de Francia con el sheriff de Uasan, informe de Gianatelli Gentile, 14 febrero, anexo a Malmusi-Blanc, 18 febrero, ib. 20.

26 Subsistía el recelo de los alemanes hacia sus vecinos. Pese a la visita la escuadra francesa a Kiel, cuando se inauguró el Canal, creían que los franceses no habían renunciado a revisar el Tratado de Frankfurt. «L'Alliance Franco-Russe», en L'Italie (Roma) 8 juillet, 1. Es un comentario a un artículo firmado por Whist aparecido en Le Figaro (Paris). 
Unido en África ${ }^{27}$, había causado satisfacción en Berlín ${ }^{28}$. En Viena sentían un «interesse simpatico». El emperador Francisco José se alegró por el recibimiento cordial que tuvo la flota italiana cuando visitó Inglaterra ${ }^{29}$.

La reacción del gobierno alemán era muy significativa. Un acercamiento italobritánico afectaría a su política exterior ${ }^{30}$, pues podría anunciar el ingreso del Reino Unido en la Triple Alianza ${ }^{31}$. En el encuentro del canciller Chlodowig Hohenlohe-Schillingsfürst y su colega el conde Agenor Goluchowski von Golochovo en Ischl se habló también de los acuerdos de Italia con España. Los dos cancilleres estaban por una renovación sin reformas. No se podría ir más adelante. Honhelohe deseaba ligar a España con la Triple Alianza, y juzgaba secundario el vínculo. Se impedía así que el gobierno de Madrid se echara en manos de Francia ${ }^{32}$.

En Madrid, el embajador francés explicó al ministro de Estado «le sens pacifique de "cette alliance» franco-rusa. Su gobierno no deseaba complicaciones en el Mediterráneo, ni siquiera a su favor. Pretendía con estas palabras neutralizar la labor de Drummond Wolff, que presentaba a la República Francesa como la responsable de todas las convulsiones que afectaban a Europa, por sus pretensiones en Egipto y Marruecos. El embajador inglés buscaba crear dudas y lo estaba consiguiendo entre quienes no tenían una visión clara de la realidad europea. Ponía ante el duque de Tetuán el giro en la política inglesa al regresar al gobierno los conservadores. Ese fortalecimiento beneficiaría a los amigos de su país. España recibiría asistencia en sus relaciones con Estados Unidos para resolver la guerra en $\mathrm{Cuba}^{33}$.

\footnotetext{
27 Promemoria, 14 julio, enviada a Ferrero por Blanc el 17 de ese mes y comunicada a B. H. Bülow, entonces embajador alemán en Roma. ASD CV 2/1.

${ }^{28}$ La reacción favorable de Guillermo II, Riservatissimo per lei solo, 217 Blanc-Ferrero, 20 octubre y 3 noviembre de 1895 , ib. $2 / 1$.

${ }_{29}$ Costantino Nigra, embajador en Viena, señalaba que La Correspondence de Paris había destacado las muestras de moderación y las garantías de paz en el discurso de Antonio Blanc pronunciado en la Cámara de Diputados. 2089/619 Nigra-Blanc, 31 julio, ib. 211.

30 Tras la entrevista de los dos cancilleres en Ischl, «debbo riconoscere che le elezioni inglesi e le dichiarazioni fatte da Vostra Eccelenza alla Camera circa le nostre relazioni colla Gran Bretagna sono avvenimenti di grande importanza per la Germania a possono produrre sulla sua politica sostanziali mutamenti». T.c. 1455 Riservatissimo G. Calvi-Blanc, 4 agosto. Sobre la cuestión búlgara y el encuentro de Ischl, informe del encargado de negocios en Berlín, 1456 Calvi-Blanc, 7 agosto. Se envió copia a Constantinopla, San Petersburgo, Londres, Viena, y Sofía, 4 septiembre, ib. 211 :

31 Esa era la conclusión del gobierno de Berlín. La prensa alemana estaba segura de que los ingleses, un pueblo práctico, no se pararían a medio camino. t.c. Calvi-Blanc, 21 agosto. Copia a Constantinopla, San Petersburgo y Viena, 4 septiembre, ib. 211.

32 «I due Ministri furono d'accordo nel pensare che non è possibile ottenere dalla Spagna una intesa che non sia strettamente segreta, perchè la Spagna e il suo governo, pur non avendo predilezioni per la Francia, non si disporranno peró mai a compromettersi pubblicamente contro di essa». 2202/651 Nigra-Blanc, 8 agosto, ASD CV 9/5. Sobre esta negociación y su fracaso; «Entre Francia a Italia. El acuerdo verbal hispano-italiano de 1895», Hispania (Madrid)192 (1996) pp. 291-322.

33 «C'est ainsi que mon collège anglais a laissé entendre au Duc de Tetuan que Lord Salisbury était disposé à faire entendre au gouvernement des États-Unis un langage ferme sur ses devoirs envers una nation amie». 102 Reverseaux-Hanotaux, 10 agosto, AAE CP 927 149-150.
}

Hispania, LXV/2, núm. 220 (2005) 643-682 
Los acontecimientos del verano de 1895 agudizaron la pugna entre ingleses y franceses. El embajador francés estaba seguro de la lealtad de los gobernantes españoles. Nunca se embarcarían en un proyecto hostil a Francia ${ }^{34}$.

Si no se llegaba a una transacción entre París y Londres, la alianza franco-rusa podría suponer un reagrupamiento de las potencias europeas. Su primera consecuencia sería la evacuación inglesa de Egipto. El peligro de que eso sucediera llevaría a los ingleses a vincularse con la Triple Alianza. Ese nuevo statu quo europeo se proyectaría en África y Asia. Como efecto de esa operación, Egipto sería para Inglaterra y Francia perdería definitivamente Alsacia y Lorena.

Se crearía así una fuerza naval invencible, integrada por las flotas de Inglaterra, Alemania e Italia. A ella podría unirse Japón, que deseaba su revancha sobre Rusia. Francia podría perder Argelia, Túnez y quizás Córcega. Una guerra prolongada acabaría con el resto del imperio colonial francés. Los «aliados» tendrían dinero. El gobierno francés no debería, por tanto, cometer el error de pensar que el Reino Unido, por temor a la guerra, no se uniría a la Triple Alianza.

Otro escenario sería la entrada de Rusia en el Mediterráneo. Londres permitiría al Zar apoderarse de Constantinopla y pactaría luego con él en Asia. En esa hipótesis, Rusia cambiaría su entente con Francia por una con el Reino Unido.

Un arreglo entre Londres y París solucionaría sus contenciosos en Egipto, y en los valles del Nilo, Níger y Mekong y en Terranova. Como compensación, Francia recibiría, de manera gradual, Marruecos, quedando Tánger como ciudad libre ${ }^{35}$. Se cumpliría ésto con los acuerdos que culminarían en el firmado en Londres el 8 de abril de 1904.

En cuanto a Italia, su iniciativa en África tenía su origen en Londres. El desacuerdo y el conflicto posterior con el Negus permitió la intervención rusa a favor de los abisinios. De ese modo el Zar combatía a sus enemigos ingleses en sus aliados italianos ${ }^{36}$.

\footnotetext{
34 «Jamais nos rapports ont été plus cordiaux avec l'Espagne qu'après l'arrivée de Tetuan au pouvoir». L.p. Reverseaux-Hanotaux, 19 agosto, ib. 168.

35 «L'Inghilterra a la situazione europea», en $L^{\prime}$ Osservatore Romano (Roma) 14-15 agosto 2. Es un resumen de un artículo aparecido en The Spectator sobre las relaciones entre Inglaterra y Francia, El diario oficioso de la Santa Sede compartía este análisis y advertía a Francia, su mejor apoyo internacional en ese momento, que no creyera que el Reino Unido consentiría un trato hostil. El gobierno de Londres devolvería golpe por golpe.

Sobre el contexto en que se concretarán muchas de estas previsiones en los acuerdos de abril de 1904, «España y Marruecos. Antecedentes de los acuerdos con Francia (1898-1904): Ciencia y memoria de África. Actas de las III Jornadas sobre "Expediciones Científicas y africanismo español, 1898-1998, Alejandro R. Díez Torre (editor), Universidad de Alcalá 2002, pp. 197-225.

36 Comentario de un político austríaco, publicado en la Neue Freie Presse, el diario liberal oficioso de Viena. "L'Italia è andata in Africa a montare la guardia per l'Inghilterra, esa vi fa fedelmente la parte di sentinèlla per lei, che domina nel1' Egitto e nell' India e si prepara per prima l'allarma in caso di pericolo ed a sostenere occorrendo il primo urto dei nemici». "Italia e Inghilterra», L'Osservatore Romano, (Roma) 21-22 agosto, 1. La empresa colonial de Italia no se dirigía desde el ministerio de Asuntos Exteriores, por eso escapaba al control parlamentario.
} 


\section{ITALIA, FranCia y TÚNEZ}

Los intransigentes de la derecha francesa abrieron la controversia con Italia a propósito del tratado de comercio firmado con el Bey de Túnez el 6 de septiembre de 1868. Tenía una vigencia de 28 años. Con su estatuto de nación más favorecida, podría introducir Italia sus productos en Francia, diciendo que eran tunecinos, porque Túnez no pagaba franquicia en sus relaciones comerciales con Francia ${ }^{37}$.

¿Se abría de nuevo la cuestión tunecina, que tuvo un papel tan decisivo en el diseño de la Triple Alianza? William Henri Waddington, ministro francés de Asuntos Exteriores, afirmó que la posición de Francia en el sur del Mediterráneo contó con el consentimiento de Inglaterra ${ }^{38}$. Esta afirmación, hecha al calor de su campaña para el Senado a finales de 1893 , necesitaba ser confirmada 39.

Salisbury habría dejado entender a Waddington en 1878 que el gobierno inglés no plantearía dificultad alguna en las relaciones que Francia estableciera con el Bey de Túnez. Aceptaba de antemano el destino posterior que pudiera tener aquel territorio y admitía que su final lógico sería completar las posesiones francesas en el norte de África. En aquella fecha, Salisbury estaba persuadido de que ningún gobierno inglés aceptaría una anexión. Para evitarla, recurriría incluso a las armas. Con todos esos datos, concluía Waddington, se consentía el protectorado pues se dejaba a Francia manos libres en Túnez.

En una comunicación al embajador inglés en París, Salisbury aceptaba que la presencia de Francia en Argelia, sostenida por una «force militaire imposante», suponía su influencia sobre la Regencia de Túnez. Desde hacía tiempo, había aceptado Inglaterra el hecho como inevitable y lo había admitido sin problema. Existía, sin embargo, una reserva a favor de los posibles derechos de Italia ${ }^{40}$.

37 «... ce traité italo-tunisien était une doulereuse et mortelle entrave pour notre colonie tunisienne, dont il empêchait le developpement et la prosperité». Paul de Cassagnac, «L' Italie \& Tunis", L'Autorité, (Paris) 28 août, 1. La Nazione (Roma) replicó que la denuncia de ese tratado sería un paso más en la confiscación de Túnez por parte de Francia. El acto alteraría el statu quo del Mediterráneo, garantizado por la Triple Alianza. Italia podría recurrir a sus aliados. EI diario de los nacionalistas franceses respondía que Austria y Alemania no irían a una guerra para apoyar las exportaciones italianas.

38 Fue una de las concesiones que obtuvo en el Congreso de Berlín, mientras era ministro de Asuntos Exteriores en el gobierno presidido por Jules Dufaure. Asumió Waddington la dirección del gobierno cuando fue elegido como presidente de la República Jules Grévy en 1879, dimitiendo el 28 de diciembre de ese año. Pasó luego a Londres como embajador. Al ser relevado en 1893, no consiguió ser elegido senador. Y murió pocos días más tarde de los comicios, el 13 de enero de 1894.

$39 \mathrm{G}$. Tornielli, entonces en Londres, recibió instrucciones para que averiguara si era verdad. Notó diferencias entre Salisbury y Rosebery. El primero podría haber asumido algún compromiso con Francia. Rosebery y el partido liberal parecían más libres, aunque no eludirían los deberes suscritos por su país.

40 «La France n'est pas le seul pays qui se trouve dans le voisinage de la Tunisie. Je ne suis pas en situation de connaître les opinions exactes du gouvernement italien, mais $j$ 'ai tout lieu de croire 
Pasados unos meses, Lord Granville hizo dos afirmaciones: aunque pertenecía al imperio otomano, Londres admitía sin recelo que Francia, una potencia con mayor civilización, interviniera en Túnez. Respecto a las pretensiones de Italia, no había variado la posición sostenida hasta ese momento por el gobierno inglés ${ }^{41}$.

El motivo para iniciar esa indagación sobre los derechos de París en Túnez fue la noticia transmitida por el cónsul de Italia en Túnez el 22 y el 27 de julio: la marina francesa hacía obras en las costas de la Regencia, reforzando así sus intereses comerciales con el aumento de su poderío naval en el Mediterráneo. En agosto la agencia Havas publicó que fuerzas tunecinas participaban en las maniobras que realizaba el XIX cuerpo del ejército francés.

En octubre, las relaciones franco-italianas mejoraban. Tendían a solucionarse las cuestiones pendientes. Había concordancia entre lo que decía Albert Billot y las palabras de Hanotaux. Era preciso calmar a la opinión de cada país, para que la negociación concluyera positivamente. El comercio entre los dos países había crecido. Los franceses estaban ya a favor de un acuerdo. Un grupo de diputados se apartaba del proteccionismo defendido por Félix Méline y sus seguidores $^{42}$.

\section{PACTOS Y SOLIDARIDAD ENTRE ALIADOS}

El gobierno conservador de Londres retornaba a su línea política: statu quo en Oriente y aproximación a la Triple Alianza ${ }^{43}$. La decisión coincidía con una crisis en las relaciones con Austria. Se desconfiaba de su fidelidad a los acuerdos que la unían con Italia y con Inglaterra. Cuando se denunció el tratado de comercio italo-tunecino, Alberto Blanc juzgó que su abstención en este punto supondría abandonar los intereses comunes de sus otros dos aliados en el Mediterráneo. No pensaban así en Viena. El tratado no estaba incluido en el acuerdo de febrero de 1887, al que accedió Austria en diciembre. ¿Qué postura tenía Inglaterra? Para Salisbury aquel pacto seguía vigente. La situación era muy

que l'attention du gouvernement italien a été appelée sur elle... Aucune communicatrion n'ayant été échangée entre les deux gouvernements à ce sujet...»

41 Riservatissimo 2891/811 Tornielli-Blanc, 28 agosto, con estos anexos: las cartas de Waddington al embajador de Francia en Londres, 26 julio 1878, la de Salisbury al embajador inglés en París, 7 agosto 1878 y la de Granville al embajador en París, 17 junio 1880. El despacho fue enviado a Londres, Viena y Berlín, corrigiendo el orden de los anexos, 6 y 23 septiembre 1895, ASD CV 22/2 1.

42 Comentario a su entrevista con Albert Billot, embajador de Francia en Roma, 3577/952 Tornielli-Blanc, 18 octubre 1895, ASD SP. P 53.

${ }^{43}$ Esta observación, hecha por el barón Marshall al embajador Lanza el 4 de noviembre, la confirmaba el propio Salisbury al embajador Ferrero al día siguiente en Londres. T.c. Lanza-Blanc, 5 noviembre. Transmitido a Londres, t.c. 2066 Blanc-Ferrero 6 noviembre, y respuesta ese mismo día, t.c. 1957. Las instrucciones dadas a Sir Francis Lascelles, embajador inglés en Berlín confirmaban la noticia. R. 1679/711 Lanza-Blanc, 24 diciembre, ASD CV 2/11.

Hispania, LXV/2, núm. 220 (2005) 643-682 
grave. En Roma se preguntaban por qué la escuadra italiana no podría sumarse a la inglesa con fines pacíficos ${ }^{44}$

El canciller austriaco también consideraba vigente el pacto, pese a que había variado la situación en Oriente. Salisbury mantenía su compromiso con las otras dos partes ${ }^{45}$.

Era una observación oportuna. El conde Goluchowski presagiaba la descomposición del poder del Sultán y un estado de anarquía. Le preocupaban los peligros que amenazaban a los cristianos en el imperio otomano. Austria deseaba reformas en Macedonia.

Para Italia era un logro regresar a la acción mancomunada, tras el fracaso en la cuestión armenia. Habría que actuar con rapidez. Rusia y Francia se movían. Había aparecido una cañonera rusa en Trebisonda. Podrían desembarcar en Yildiz tropas rusas. Y la escuadra francesa se dirigía desde Toulon hacia Siria, donde se temían desórdenes. Por esa razón Blanc dijo a d' Eperjesy, encargado de negocios de Austria en Roma, que, debería hacerse, con fines pacíficos, una demostración naval de los tres aliados, que frenara la acción de otras potencias llevada a cabo de forma aislada y con riesgo de guerra. Alemania podría permanecer en segundo plano. Su ayuda sería así más útili ${ }^{46}$. Para una acción naval bastaba la presencia de Inglaterra ${ }^{47}$.

Goluchowski estaba de acuerdo y Berlín también lo aprobó ${ }^{48}$. En Viena no querían que las escuadras aparecieran agrupadas por alianzas. Roma no deseaba que Austria optara por una acción aislada ${ }^{49}$.

Rusos y franceses se oponían a una demostración que obligase al Sultán a recoger las demandas de las seis potencias. Existía la sensación de que la protección

\footnotetext{
${ }_{44}$ Riservatissimo Blanc-Costantino Nigra, 6 noviembre. El embajador en Viena, entonces en Monza, respondió al ministro Blanc el día 10. Blanc-Ferrero, 12 noviembre, ASD CV 7/13 3, 5 y 7. Grenville, J: A. S.: Lord Salisbury and Foreing Policy. The Close of nineteenth Century, London 1994.

45 La posición del imperio en Bosnia-Herzegovina, desaconsejaba cualquier intervención en el contencioso de Italia con Francia sobre el tratado comercial con la regencia de Túnez. Goluchowski dijo que no creía que los tratados de la Triple Alianza y los acuerdos de 1887 implicasen solidaridad en África. Nigra-Blanc, 18 noviembre, ASD CV 7/3 23. Recibido el 21, se envió copia a Ferrero, embajador en Londres.

46 Blanc conocía que «il governo imperiale non vuole nella questione d'Oriente rompere colla politica seguita da Bismarck, che ha ancora tanti aderenti in paese. In seconda linea, peró possiamo, ripeto, contare su appoggio Germania. Questa è anche la convinzione mio collega austríaco; a risulta da tutti i discorsi Marshall, cancelliere e Imperatore stesso». T.c. 2119 LanzaBlanc, 20 noviembre, ib. 21.

47 C. 47015/421 Blanc-Ferrero, 470161452 Blanc-Lanza, 47205/870 Blanc-Nigra, y 47815/625 Blanc-embajador en Constantinopla, 12 noviembre, ASD CV 7/13 8. La respuesta de Lanza, 17 novienbre, se envió a Londres el día 20, ib. 14 y 16.

${ }^{48}$ Riservatissimo Blanc a los mismos a quienes dirigió el despacho anterior, 15 noviembre y t.c. Blanc-Ferrero, 17 noviembre, ib. 9-10.

${ }^{49}$ Había que emplear todos los medios para evitarlo. T.c. 2203 Blanc-Catalani, 17 noviembre. Sobre la posición de Austria, de la que había informado a Salisbury, t.c. 2049 Ferrero-Blanc, 16 noviembre, ib. 11 y 12 .
}

Hispania, LXV/2, núm. 220 (2005) 643-682 
del Zar frente a la presión de los otros gobiernos dejaba sin eficacia el acuerdo de ingleses, italianos y austriacos. Quejarse sin posibilidad de intervenir en defensa de la paz y del trato humanitario a las minorías ide qué servía? ${ }^{30}$.

En Berlín compartían la inquietud de Blanc. La actitud de Rusia y Francia justificaba el acuerdo de $1887^{51}$. Se había roto a su favor el statu quo en el imperio otomano. Sometido a una especie de protectorado ruso, faltaba al Sultán autoridad para negociar con Austria, Alemania, Italia e Inglaterra.

La independencia de Turquía era vital para Europa. Por los Estrechos y el Mar Negro no circulaban ya libremente más que las tropas rusas. Esa situación perjudicaba a los otros Estados y era contraría a la legalidad, en el orden interno y en el internacional.

El objetivo del acuerdo del 2 de febrero de 1887, al que se adhirió AustriaHungría en diciembre, quedaba neutralizado. Ingleses y austriacos no sabían qué apoyo político debería darles Alemania. Si no era posible unir las tres flotas, ¿qué ventajas podrían esperarse de los pactos que unían a Italia con Inglaterra y con los dos Imperios centrales? La renuncia a una acción conjunta, tal como estaba prevista en 1887, abriría la puerta a la anarquía en Turquía. Para desbloquear la situación, era preciso que los tres aliados intercambiaran «con reciproca fiducia a sinceritá» su valoración y sus puntos de vista cuando lo requirieran las circunstancias ${ }^{52}$. Austria esperaba la reacción de Alemania e Inglaterra ${ }^{53}$, pero ésta no quería despertar la susceptibilidad en Rusia ${ }^{54}$.

Entre tanto, crecía el pesimismo en España por la guerra en Cuba. Habría que sustituir al general Martínez Campos moralmente vencido. La continuidad del capitán general era «un peligro, cierto ya, evidentísimo». Estaba asustado

\footnotetext{
so Por esa razón, la escuadra italiana permanecería en Esmirna, sin entrar en contacto con las otras. El gobierno no se apartaba de la acción diplomática para ofrecer al menos la apariencia de unidad entre las seis potencias. Lettera riservatissima, texto impreso sin número, a los embajadores en Berlín, Londres y Viena, 22 noviembre, ib. 24. Blanc fijó el 28 de noviembre ante el parlamento la postura del gobierno, resumida luego en su despacho del 3 de diciembre a los embajadores en Londres y Viena.

${ }^{51}$ Había que conocer la posición de Salisbury. Se esperaba la llegada del nuevo embajador en Berlín para el 6 de diciembre. Sería una de las primeras cuestiones que se plantearían a Sir Francis Lascelles. T.c. 2218 Lanza-Blanc, 2 diciembre. Había que saber si Londres estaba con la Triple Alianza o con Rusia. 219 Blanc-Nigra, 3 diciembre. Copia ese mismo día, a Lanza y Ferrero, ib. 31 y 34-35.

52 «Confidiamo che l'Inghilterra a l'Austria-Ungheria, coll'adesione già data dalla Germanía a gli accordi del 1887, potranno cosi impedire che sia mancato, all'ultima ora, lo scopo di pace mantenuto dalla triple alleanza con successo da tanti anni». Riservatissimo e segreto Blanc-Nigra y Ferrero, 3 diciembre, ib. 36 y repetido con el n. 38.

53 Goluchowski decía que había que negociar en Londres y consultar a Berlín. Esperaba que se resolviera la cuestión de Oriente. Había que proceder con calma y conseguir que las otras dos partes asumiesen «impegni più positivi». T.C. s.n. riservatissimo per lei solo Nigra-Blanc, 7 diciembre, y Riservatissimo 366411010, 8 diciembre. Se envió a Ferrero, T.c. 2412, 8 diciembre, ib. 40, 43 y 41.

54 Por esa razón también Salisbury pedía calma. No podría guardarse el secreto de una reunión de las tres partes en Londres. 362 Ferrero-Blanc, 12 diciembre, ib. 44.
} 
tras los desastres de Matanzas. Urgía acabar con la política de perdón e indulto a los que se presentaban, que regresaban luego a la manigua ${ }^{55}$.

Las cosas no iban bien pese a los recursos puestos en marcha ${ }^{56}$. Las reformas políticas no tuvieron éxito ${ }^{57}$. El duque de Tetuán manifestó la neutralidad española en la crisis de Turquía, desmintiendo de ese modo cualquier cambio en una política, que $E l$ Heraldo calificó de aislamiento suicida, responsable de los problemas en Cuba y Filipinas. Esta postura agradaba al embajador francés ${ }^{58}$. Frenaba cualquier suposición sobre el alcance de las palabras pronunciadas por el embajador Casa Valencia en el banquete del Lord Mayor de Londres ${ }^{59}$.

\section{Tensiones EN ORIENTE y ÁFrica}

Así las cosas, Francia denunció el acuerdo de 1891 sobre límites en África oriental. Ese acto agredía a Italia. En mayo de 1894 hubo una entrevista entre Rouvier y Francesco Crispi. Fracasó porque ni Casimir Périer ni Gabriel Hanotaux creyeron sincera la oferta del jefe del gobierno italiano ${ }^{60}$.

El día 5 de ese mes se firmó en Roma un protocolo con Inglaterra, fijando la zona de influencia italiana en el Harar y Gildessa. El artículo XVII del Tratado del 2 de mayo de 1889 encomendaba a Italia negociar todos los contenciosos que tuviera Etiopía con otras potencias a las que comunicó esta estipulación en octubre de aquel año.

El trazado de las respectivas zonas se recogía en el acuerdo anglo-francés del 2 de febrero de 1888, del que. Inglaterra informó confidencialmente a Italia. Su artículo 4 vetaba a cada una de las partes intervenir en el Harar o ponerlo bajo su

ss Vid. una extensa carta de Eva Canel a Cánovas, 29 de diciembre. Ese mismo día escribió también Eduardo López Dago, director de de La Habana. La manifestación de apoyo que hubo en La Habana fue preparada por los funcionarios del Gobierno General de la Isla. La gente, como indicó también Canel, pedía que asumiera el mando Camilo García Polavieja, Valeriano Weyler o Ramón Blanco, AGP 15/5 V E.

56 129 y 138 Reverseaux-Pierre Berthelot, 26 noviembre y 16 diciembre, AAE CP Espagne 927 256-259 y 282-283.

57 Inés Roldán Montaud, La Restauración en Cuba. El fracaso de un proceso reformista, Madrid, Consejo Superior de Investigaciones Científicas, 2000, pp. 528-627.

58 El ministro de Estado dijo al embajador frances: «... notre politique doit être... l'abstentionn dans toutes les affaires qui ne touchent pas personanellement l'Espagne. Nous tenons à être bien avec tout le monde sans engager notre liberté d'action envers ce qui soit». "Ces paroles méritait d'être retenues pour les rappeler à l'occasion». 122 Reverseaux-Pierre Berthelot, 17 noviembre, AAE CP Espagne 927 236. Berthelot acababa de asumir la cartera en el gabinete presidido por Léon Bourgeois, tras la dimisión de Alexandre Ribot.

59 124 Reverseaux-Berthelot, 17 noviembre, ib. 238-239.

60 Albert Billot, «Un épisode des relations franco-italiennes. L'entretien Crispi Rouvier (1894)», en Revue d'Histoire Diplomatique 71 (Paris) (1957) pp 289-292. El texto comenta una entrevista con Rouvier, el 15 de noviembre de 1904, en la que se habló de un libro que narraba el hecho.

Hispania, LXV/2, núm. 220 (2005) 643-682 
protectorado. $\mathrm{Al}$ ser un convenio meramente negativo, los ingleses no lo violaron al desentenderse en favor de Italia. Si Francia tenía derecho a oponerse, debió haberlo hecho en octubre de 1889, es decir, cuando el gobierno de Roma notificó su protectorado sobre Etiopía, a quien pertenecía el territorio. Desde el 2 de mayo de aquel año así lo aceptaron las naciones amigas, mientras Francia no cesó de replantear un asunto ya pactado.

El protocolo del 5 de mayo de 1894 suponía, por parte de Londres, reconocer el Tratado de 1889. En él se otorgaba a Inglaterra de forma provisional y hasta que Italia no hiciera efectivo su control sobre la región, la vigilancia de las fronteras con el Harar. De esta manera se paraban los manejos de Francia y se le obligaba a cumplir la cláusula de «desinterés» convenida por ella con Londres ${ }^{61}$.

La renovación de la Triple Alianza desencadenó en París una respuesta, que el ministro Blanc juzgó una provocación ante la cual no deberían quedar pasivos los amigos de Italia ${ }^{62}$, situada en una encrucijada dramática: guerra desde la debilidad o paz renunciando a sus derechos ${ }^{63}$. No podría modificar sus relaciones con las potencias europeas hasta enderezar la situación en África, donde, para retornar a los confines militares trazados, habría que preparar una nueva campaña. No se trataba de una cuestión de honor ${ }^{64}$.

Días antes, el 19 de diciembre, la Cámara italiana aprobó un orden del día presentado por los diputados Torrigiani y Garibaldi y aprobado por Crispi otorgando la confianza al gobierno y concediendo 20 millones de liras para la campaña de Etiopía ${ }^{65}$.

61 "Nell'escludere l'azione francese dall Etiopia a dalle sue dependenze confidiamo che l' Inghilterra e l'Italia si considereranno solidali e che riguarderanno siffatta esclusione come un interesse loro comune». R. s.n. Le pretese francesi sopra l'Harar, documento impreso, varios ejemplares, ASD SP P 52.

${ }_{62}$ Sin apelar al casus foederis, quería recordar que «in altre circostanze bastò un loro contegno di ferme osservazioni alla Francia, perchè questa desistesse da atti che, nel presente caso, potrebbero essere qualificati di provocazione». Riservatissimo bis 192 Blanc-Ferrero y Lanza, 17 diciembre 1895. El interés de Alemania por la presencia italiana en África, 266 Lanza-Blanc, 31 diciembre. El momento de las relaciones bilaterales, tal como las había valorado Holstein, segreto s.n. LanzaBlanc, 2 enero 1896, ASD CV 2/3.

63 «Nella guerra moderna che Francia e Russia ci fanno nell'Eritrea senza che la triplice ci assista in alcun modo, l'indifferenza anche dell'Inghilterra non ci lascia altra alternativa che guerra a fondo con nostra impotenza in Europa o pace con protettorato francese sull'Harar e russo sullo Scioa». R. personale Blanc-Ferrero, 24 diciembre, ib. 213.

64 «Temo che mondo politico italiano abbia torto considerare ultimi fatti Africa come questione di onore da reivindicare». T.c. 254 Ferrero-Blanc, 26 diciembre, ib. 2/3.

65 «La Camera, confidando che il governo saprá tenere alto il prestigio delle nostre arme, ristabilire la pace nei possedimenti africani e proveddere alla sicurezza per l'avvenire, affermandosi contraria ad una politica di espansione, prende atto delle dicchiarazioni del governo e passa a la discussione dell'articolo unico della legge». La confianza se votó por 255 contra 148 y el crédito por 272/36. "Parlamento italiano. Camera dei Deputati», en I1 Popolo Romano, (Roma) 20 dicembre, 12. Un comentario del debate, 276 Benomar-Tetuán, 20 de diciembre, AMAE H 1622. Para la situación militar en Etiopía en 1894, vid. MCCR 665/8 1-21. 
¿Qué pensaba Alemania sobre la crisis de Oriente y la conducta que deberían tener Austria-Hungría, el Reino Unido e Italia, firmantes de los acuerdos de 1887? La necesidad de comprometer más al gobierno de Londres confirmaba su resolución de permanecer en segunda línea. No habría que hacerse ilusiones. El gobierno inglés no correría el riesgo de una guerra, pues no se encontraba en condiciones de afrontarla ${ }^{66}$.

La reserva inglesa aseguraba a los alemanes que ninguno de los tres «aliados» de 1887 iría a una guerra con Turquía. Inquietaba a Alemania la incidencia de los posibles desórdenes en Macedonia en las relaciones entre rusos y austriacos ${ }^{67}$. El canciller alemán tomó nota de lo convenido en 1887: intercambiar ideas entre Viena, Londres y Roma siempre que surgiera un problema político que afectara a los intereses de alguno de los tres gobiernos en Oriente ${ }^{68}$.

El consejo del canciller Hohenlohe de actuar con prudencia no era vano. Llegó a Roma la noticia de que mandaban las tropas del negus Menelik II oficiales franceses ${ }^{69}$. Fue desmentida desde París. Había deseo de llegar a un arreglo para delimitar los territorios de Francia e Italia en África ${ }^{70}$

Las dos partes tenían buena voluntad. Gabriel Hanotaux estaba dispuesto a concluir un arreglo comercial ${ }^{71}$. La contrapartida para que los aceptaran la oposición parlamentaria y la opinión francesa sería un acuerdo sobre Túnez. En unas semanas podrían desaparecer dos cuestiones que perturbaban las relaciones franco-italianas ${ }^{72}$. Tornielli creía que la oferta era buena. Francia estaba en Túnez desde hacia quince años. Y ese hecho creaba derechos ${ }^{73}$.

\footnotetext{
${ }^{66}$ Esa conclusión se fundaba en la moderación con Estados Unidos. En Berlín creían que era una muestra de debilidad.

${ }^{67}$ El conde Kapnist, embajador ruso en Viena, había recibido instrucciones, para que cada uno de los dos Imperios ejerciera su influencia en Constantinopla y en Sofía a fin de evitar incidentes en la región.

${ }_{68}$ Conversación de Costantino Nigra con el príncipe Clovis de Hohenlohe, en visita a Viena por motivos familiares. Los dos habían coincidido en París, cuando Hohenlohe fue embajador de Alemania. Nigra habló de las fiestas del centenario de la «conquista» de Niza por parte de Francia. A los actos asistiría el presidente de la República. Félix Faure aseguró que se utilizaría un lenguaje correcto. El gobierno italiano deseaba que sus amigos ordenaran a sus cónsules en la ciudad que no asistieran a los festejos. Riservatissima s.n. el texto impreso, Nigra-Blanc, 30 diciembre, recibido el 4 de enero y enviado el 14 a Londres y Berlín, y el 20 de enero a Constantinopla, lb. 21347.

69 Sobre las dificultades creadas por la actitud francesa y el apoyo alemán ante Londres en la campaña del general Baratieri en 1895, MCRR 665/6 (1-21) y 7 (1-11).

70. Sobre un arreglo en Etiopía y el Harar, vid. la Memoria impresa, del 20 de febrero de 1895 , y las cartas de Blanc al embajador en París, con copia a Londres, Berlín y San Petersburgo, 31 marzo, MCRR 665/12 (14 y 15).

71 Sobre las condiciones, MCRR 66514 (1-4).

72 T.c. Blanc-Tornielli y respuesta, 20 diciembre 1895. Los signos de amistad de Francia hacia Italia, t.c. 23 de diciembre, ib. (7-8 y 10).

73 T.c. Tornielli-Blanc, 24 diciembre. Se envió a Crispi. Este se mostró partidario de aceptar, BlancCrispi y Crispi-Blanc, 24 y 25 diciembre, ib. 17, (11 y 13). Esos días hubo una comunicación constante, toda ella muy reservada, entre Blanc, Crispi y Tornielli, de la que queda constancia en MCCR 665/3.
} 
Era posible hallar un terreno común, un punto de encuentro para las dos naciones $^{74}$. A principios de enero, había acuerdo ${ }^{75}$. Se mantendría en secreto. Su publicación debería sujetarse al calendario parlamentario francés. Estaban pendientes el debate del acuerdo con Inglaterra en Siam y una interpelación sobre política exterior. Era necesario preparar a la opinión. Muchos no entenderían por qué se concedía ahora lo que se negó en 1891. ¿Había una orientación nueva en el ministerio de Asuntos Exteriores francés? Esperar era una opción sabia. No podrían tomarse decisiones en momentos de malhumor. La negociación siempre es un proceso complicado. Italia debía tener presentes su situación en África y la incertidumbre que había en Europa ${ }^{76}$. La responsabilidad debería impedir que en el camino se interpusieran obstáculos como la campaña que esos días hacía la prensa italiana contra Francia ${ }^{77}$.

El recelo entre las potencias llevaba a proyectar sobre el adversario idénticos temores a los que él sentía. Al iniciarse 1896, Paul Cambon advertía al presidente de la República sobre el riesgo de que Francia quedara al margen de la solución que se diera a las cuestiones de Oriente. Inglaterra podría alcanzar la hegemonía en la zona, pues Rusia tendría que apoyar a los armenios de Turquía, si quería impedir el contagio de los armenios súbditos del zar.

\section{LAS DUDAS DE ITALIA}

La política oscilante de Berlín entre Inglaterra y Rusia iba decantándose hacia esta. Guillermo II esperaba obtener beneficios de la antipatía entre franceses a ingleses y que los dos gobiernos tuvieran que aceptar los pactos entre Berlín y San Petersburgo. Francia tenia que cuidar sus relaciones con Rusia ${ }^{78}$. No había que olvidar que el gobierno italiano había decidido intervenir ${ }^{79}$. Eso lesionaba el interés de Francia, a quien convenía el statu quo. Lograr ese objetivo implicaba una nueva política ${ }^{80}$.

\footnotetext{
${ }_{74}$ T.c. Blanc-Tornielli, 19 enero, lb. (10).

75 Las instrucciones verbales sobre cláusulas comerciales a intercambio de territorio en el este de África las llevó Panizzardi personalmente a París. T.c. Tornielli-Blanc, 14 y 18 enero 1896, ib. (5 y 9).

76 T.c. Tornielli-Blanc, 21 enero. El 29 de enero, el ministro Blanc envió una memoria detallada, ib. (12, 13 y 16). Para la situación militar en Etiopía, «Memoria dell'Ufficio Coloniale» remitida a Crispi y Blanc, 15 enero 1896, MCRR 665112 (20). Hay otras dos memorias enviadas el 2 y el 28 de febrero, ib. (4-5)

77 El interés recíproco exigía que se apaciguaran las pasiones, t.c. Tornielli-Blanc, 29 enero, ib. 14.

78 «Elle a autant besoin de nous que nous avons besoin d'elle et je suis sûr qu'elle se résignerait à nous traiter... d'égal à égal si nous le faisions entendre que nous désirons qu'il en soit ainsi», decía el diplomático.

79 «M. Crispi a M. Blanc ont souhaité une intervention; ils y ont poussé l'Angleterre en lui proposant de se mettre à sa remorque et leur empressement n'a pas peu contribué a refroidir le ministère anglais. Je sais du reste que l'Allemagne et surtout l'Autriche se sont employée à calmer leur allié».

80 «Malgré la haute valeur des hommes en France et leurs bonnes intentions, nous ne pouvons raisonnablement exiger d'eux une action raisonnée et continue puisqu'ils apparaissent et disparaissent
} 
La cuestión de Oriente afectaba a las relaciones de Italia con Inglaterra y con Austria-Hungría. Francis Clare Ford, embajador inglés en Roma, informó al ministro Blanc que Nicolás II había garantizado la seguridad del Sultán de Turquía. Para eso había ocupado por diez años seis provincias de Anatolia, entre Diyarbakir y Trebisonda. Además de reducir su deuda con ella, Rusia le proporcionaría ayuda financiera ${ }^{81}$.

Dudaba Blanc de que Rusia se hubiera apoderado de territorios del imperio otomano. No deseaba su reparto. La posición preponderante que ejercía en la corte del Sultán le bastaba. Expulsadas las escuadras occidentales de los Estrechos, los rusos los controlaban de forma exclusiva ${ }^{82}$.

En cuanto al arreglo con Francia en África, Blanc deseaba conocer si había variado la posición del gobierno inglés tras la declaración que hizo el 5 de mayo de 1894 sobre el protectorado italiano en el Harar. Italia tenía que aceptar los límites que Francia propuso en 1891 . No podía responder de otro modo. Por su parte, Londres tenía igualmente que confirmar la nota que Lord Kimberley envió al embajador en París el 17 de julio de 1894.

La imagen de Inglaterra en Italia se había deteriorado tras la prohibición de una acción del ejército italiano en Zeila, cuyo efecto moral sobre las tropas del negus habría beneficiado a las italianas.

La conclusión del gobierno de Roma era neta: «L'Inghilterra rinnega la comunanza d'interesse italo-inglese affermata colla dichiarazione del 5 maggio 1894». Eso suponía echar a Italia de Kassala. Era una concesión a Francia, que no habría perdonado el apoyo dado por los italianos a los ingleses. Esta doble exclusión, de Zeila y de Kassala, no sería un gesto amistoso por parte inglesa. Cuando hubiera una propuesta formal, el embajador Ferrero debería abstenerse en favor de una negociación entre el embajador inglés y el ministro Blanc.

La otra potencia amiga, Austria-Hungría, unida a Inglaterra, negociaba con Francia el régimen comercial en Túnez. Las cosas se decantaban a favor del bloque franco-ruso y en contra de la paz ${ }^{83}$. Sufría además Italia la desconfianza

\footnotetext{
comme des météores». Paul Cambon-Félix Faure, 10 enero 1896, «Lettres de Paul Cambon, ambassadeur de France, au Président de la République, Félix Faure», en Revue d'Histoire Diplomatique (Paris) 68 (1954) pp. 191-195. Sobre Paul Cambon, ViluATE, Laurent: La république des diplomates. Paul et Jules Cambons 1843-1935, Paris, Science Infuse, 2001.

${ }^{81}$ Pendiente la aceptación de estas condiciones, habría que recordar que el principal consejero del Sultán era Mahmud Gallal-el-Din, al que se consideraba un agente ruso. Su hijo acababa de ser nombrado embajador turco en París.

82 Blanc no quiso apelar en ese momento a la cláusula, incluida a petición de Salisbury, sobre Armenia que existía en los acuerdos de febrero y diciembre de 1887 y ligaban a Austria-Hungría, Inglaterra e Italia.

${ }^{83}$ Se había producido una situación grave, "che risulta dall'essersi rese ineffettive le alleanze, illusorie le comunanze d'interessi, e per conseguenza precaria la pace, e favorevoli al gruppo francorusso le condizioni di una guerra europea». S. n. texto impreso, Blanc-Ferrero, 11 enero 1896, ASD CV $7 / 348$.
}

Hispania, LXV/2, núm. 220 (2005) 643-682 
de su poderosa aliada. Alemania no veía bien su relación directa con Londres ${ }^{84}$. Adolf Marshall von Bieberstein y Friedrich von Holstein insistían en las ventajas que reportaba a Italia su permanencia en la Triple Alianza. Si Inglaterra persistía en su aislamiento, habría que aproximarse a Rusia. Esta debería ser la estrategia: cautela de Austria-Hungría y de Italia en sus relaciones con Inglaterra; que el gobierno de Crispi demostrara ante el de Londres su interés en continuar en la Triple Alianza y destruir los temores del Zar sobre los objetivos de esta. A ese plan se ajustaban las frecuentes conversaciones del embajador alemán, conde Paul Hatzfeldt-Wildenburg, con Salisbury, las de Holstein y Marshall con el embajador italiano, Carlo Lanza, y la carta de Guillermo II a Nicolás II85.

La fluctuante política inglesa inquietaba también a Viena. Estaba casi congelada la comunidad de intereses entre las tres aliadas mediterráneas y de estas con Alemania. ¿Habría que advertir sobre la situación a Berlín y a Londres? Admitiendo la buena voluntad de Viena, Blanc creía que los italianos deberían dar ese paso, salvando así su deber moral en un momento en que se acentuaba la inclinación de los dos imperios centrales hacia Rusia.

El embajador austriaco en Roma, el barón Marius Pasetti von Friedenburg, no conocía las informaciones proporcionadas a Blanc por Clare Ford y sospechaba. No necesitaba el Sultán de Turquía más apoyo que el monopolio de la presencia naval rusa en los Estrechos. ¿Qué razones tenía Blanc para empujar a sus aliados a la acción, tal como denunciaba Paul Cambon ante el presidente Félix Faure? El haber contemporizado en el caso de los armenios habría agravado las consecuencias de la crisis de Oriente extendiéndolas a los Balcanes. El resultado de ese desinterés de los aliados de Italia era el predominio francés en el Mediterráneo occidental, y ruso, en el Mediterráneo oriental.

Austria-Hungría había aceptado en Túnez que Francia gozara de los mismos derechos que ella en Bosnia y en Herzegovina, con una diferencia, los suyos tenían sanción internacional y Francia no la había recibido para ejercer un protectorado en Túnez. ¿Era el precio pagado por el apoyo francés en el Congreso de Berlín? ${ }^{86}$ Extrañaba y ofendía a Italia que sus dos aliados nada hubieran hecho para que el gobierno francés evitara los ataques a sus fuerzas en Abisinia desde el Obock (Yibuti). No tutelaba, desde las fronteras que Italia le había reconocido en 1891, el protectorado italiano.

Era su represalia por la renovación de la Triple Alianza. De esta manera, según Blanc, rusos y franceses comprobaban que los compromisos secretos adquiridos por los tres aliados eran ineficaces para Italia, tanto en los hinterlands del nor-

${ }^{84} \mathrm{La}$ reivindicación de la autonomía de la política exterior de Italia, especialmente con el Reino Unido, 93 y 98 Blanc-Ferrero y Catalani, 17 y 18 enero 1896, ib. 51-52. El gobierno no necesitaba permiso de Alemania para negociar con los ingleses.

85 Segreto 119140 Lanza-Blanc, 24 enero 1896, ib. 71358.

${ }^{86}$ De eso modo, una potencia amiga, "cointeressata coll' ltalia nel Mediterraneo, contro il procedimento della Francia, quando questa ci dichiara per esempio, come ha dichiarato, che i nostri provvedimenti di ordine in Sicilia l'obbligavano a fortificare Bizerta». 
te de África, afectados quizás por un acuerdo franco-alemán, como en los hinterlands de Eritrea, abandonados a la injerencia cada vez mayor de rusos y franceses.

La situación se hacía insoportable para Italia ${ }^{87}$. Sin la solidaridad mediterránea de sus aliados en África, su presencia y acción en Oriente se reducían a un recuerdo histórico. Sus dos aliados de 1887 no percibieron su aportación frente al paneslavismo y dejaban vía libre a un protectorado ruso en aquella zona después que sus tropas se apoderasen de Constantinopla.

Entre tanto las dos potencias centrales evolucionaban no sólo hacia una federación de los tres emperadores, un «Kaisersbund», sino hacia el bloque francoruso $^{88}$. El cuadro internacional en el que se había fraguado la Triple Alianza se había roto, al no conseguir atraerse al Reino Unido ${ }^{89}$. La lealtad de Italia la había convertido en blanco de los golpes de rusos y franceses ${ }^{90}$. El conde Franz Deym, embajador de Austria-Hungría en Londres, tenía el encargo de sondear a Salisbury sobre la conveniencia de precisar y dar eficacia a los acuerdos de 1887 a insistir en estos dos puntos: mantener el statu quo en Turquía y en los Estrechos y actuar unidos siempre que se atentase contra él, dejando a Inglaterra la iniciativa, pues era la potencia más interesada? ${ }^{\text {} 1}$

Eran ambiguos Holstein y Marshall en sus conversaciones con Lanza. En la que sostuvieron en Roma el barón Pasetti, Blanc y Nigra, entonces en la ciudad, el embajador austriaco aseguró que no existían reticencias de Alemania hacia la renovación del acuerdo de las dos potencias con Inglaterra, a quien se juzgaba excesivamente condescendiente con Francia y Rusia en detrimento de los intereses austriacos e italianos.

La renovación de los acuerdos de 1887 podría negociarse en Londres. Había una lista de quejas contra los gobiernos ingleses en el imperio otomano, en África oriental y en los hinterlands al sur de Tripolitania. La cooperación en Kassala y el Harar permitía esperar mayor solidaridad en el Mediterráneo, pero «l'Inghilterra ci abbandona a favore della Francia», aceptando su tesis de que el

\footnotetext{
87 «... l'Italia fu posta nella impossibilità di stabilire colla Francia stessa relazioni di buon vicinato anche coloniale, fondate sugli atti di Berlino e di Bruselles, finchè non sia uscita dalla triplice allleanza, condizione questa sistematicamente ripetutaci dal signor Billot, in ogni questione di miglioria delle relazioni politiche o commerciali di due paesi».

${ }_{88}$ En ese contexto era revelador el conflicto creado por Guillermo II con su carta al presidente Stephanus Johannes Paulus Krüger, que ofendió a los ingleses, enfrentados a los boers en el Transvaal. Mejoró la situación tras la carta del emperador alemán a la Reina Victoria. Goluchowski confesaba que nada podía hacer para que Guillermo II evitase gestos que dañaban a los aliados y lesionaban los intereses alemanes. Riservatissima Nigra-Blanc, 15 enero, íb. 50.

${ }^{89}$ De ese modo, la alianza «è condotta sia ad appoggiarsi sulla Russia sia anche a soddisfare con ogni concessione possibile la Russia in Asia e la Francia in Africa».

90 Segreto, texto impreso s.n. Blanc-Nigra, 12 enero 1896, ASD CV 7/3 49.

91 Goluchowski deseaba además que se mirara con una especial atención a Bulgaria. Si cayese del lado ruso, la posición de las tres aliadas se debilitaría. Quería que Ferrero recibiese las mismas instrucciones para que los dos embajadores siguiesen una misma línea. Riservatissima Nigra-Blanc, 30 enero, ib. 60.
}

Hispania, LXV/2, núm. 220 (2005) 643-682 
protectorado italiano en el Harar modificaba el statu quo en la zona. Italia tuvo que afrontar en esas condiciones la guerra colonial, alejarse de Oriente y aceptar que sin el Harar la empresa en el Mar Rojo era inviable. El acuerdo entre Rusia y Francia obligaba a Italia a desinteresarse de la expansión rusa en Oriente, sobre todo, tras las propuestas que Inglaterra hizo al Zar sin comunicarlas previamente a Viena y Roma.

Italia decidió limitar sus objetivos a concluir la guerra en Abisinia, «declinando la responsabilità della condizione in cui furono lasciati gli che più importavano all'Inghilterra e a noi nel Mediterraneo». Desde ella había que encarar el desenlace de la negociación en Londres. Si fuera negativo, habría que proceder a un intercambio con los dos socios de la Triple Alianza para proceder a su redefinición, «acciochè fra $i$ nostri interessi in Oriente, a cui è estranea la Germania, ed ai nostri interessi in Africa, a cui è estranea l'Austria-Ungheria, non manchi quel nesso chi si era trovato negli accordi del 1887 , a che risultó annullato dalla persistenza dell'Inghilterra a non dare alcun pratico seguito agli accordi medessimi»’2.

Al enviar copia del despacho de ese. mismo día al embajador en Londres, el ministro advertía a Lanza que el gobierno italiano esperaba poco de la negociación con Austria e Inglaterra. La emprendía por lealtad al deber que se impuso de servir de lazo entre esta y la Triple Alianza. Lo hacía superando el malestar creado por la falta de orientación fija en la política internacional del partido conservador, que había regresado al poder en Londres. Por amor a la paz, el gobierno presidido por Crispi había quitado aspereza a sus relaciones con Francia y Rusia, a las que había mostrado su disposición para concluir acuerdos sobre asuntos pendientes. Lo había hecho Alemania. Lo podría hacer Italia sin traicionar sus alianzas ni la amistad con otras naciones.

Había quitado importancia al apoyo moral y material que Rusia había prestado al negus Menelik II y había aceptado la explicación del ministerio ruso, a pesar de que la desmentían los hechos. Con Francia había mostrado su disposición a clarificar los contenciosos que deterioraban las relaciones mutuas: el tratado de comercio, los límites en Africa y la cuestión de Túnez ${ }^{93}$. Era desalentador el poco aprecio que hacía Francia a la intervención alemana para asegurar su interés a favor de Italia en las dificultades que encontraba en África, provocadas en gran parte por su actuación, al negarse a continuar la negociación sobre límites iniciada en $1891^{94}$.

\footnotetext{
92 Blanc pedía al embajador Ferrero que expusiera estos puntos de vista con claridad y que apelara a la lealtad de Lord Salisbury. Segreto 59 Blanc-Ferrero, 2 febrero 1896, ASD CV 7/3 59, impreso s.n. ib. 61.

93 De ese modo, como podría probar el embajador en Berlín con fehacientes documentos, Italia había seguido los consejos de Holstein y Marshall.

94 «Vengono dunque singolarmente diminuiti e compromessi per noi quei benefici della pace che ci dovrebbero essere guarantiti dalla Triplice Alleanza». Segreto, texto impreso s. n., BlancLanza, 2 febrero, ASD CV 7/13 62.
} 
La inestabilidad del gobierno conservador explicaba la política fluctuante de Salisbury en Oriente. La guerra del Transvaal y el contencioso con Venezuela acentuaron ese sentimiento de desorientación. Aunque hubiera algún sector partidario de una mayor beligerancia, los ingleses eran pacifistas ${ }^{95}$. Situado en un terreno donde había que moverse con una cautela que parecía cálculo o ambigüedad, «nessuno potrá contestare, in ogni circostanza, sia pubblica che privata, (che) è costante per parte del primo ministro a dei membri del Gabinetto l'espresione d'amicizia e di solidarietà verso l'Italia». Como ejemplo, el discurso pronunciado en Bristol el 3 de febrero por Lord Arthur James Balfour, ministro del Tesoro ${ }^{96}$. No era oportuno ni aconsejable forzar a Inglaterra a asumir compromisos formales. Su condición de potencia imperial le exigía ser prudente. No podría ignorarse que, en caso de guerra en Oriente, los ingleses necesitarían la flota y los puertos militares italianos ${ }^{97}$.

Tras la negociación, Salisbury quería mantener los acuerdos, pero AustriaHungría los consideraba insuficientes y poco prácticos. Ferrero dejó a su colega austriaco la iniciativa. Salisbury habló de la conveniencia de modificarlos, pero la situación de su gabinete y la reacción de la opinión le impedían hacer «qualsiasi convenzione scritta» ${ }^{98}$. No le consentiría ir a una guerra en Oriente.

Dar eficacia al acuerdo suponía para Austria oponerse militarmente a que Rusia ocupara Constantinopla. Consentir eso frenaría los movimientos que amenazaban Macedonia, pero supondría un coste muy alto: confirmar la pérdida de influencia de la Triple Alianza en Turquía99.

\section{LA NUEVA SITUACIÓN Y CUBA}

Desde el 10 de marzo de 1896 ocupaba el ministerio de Asuntos Exteriores italiano Onorato Caetani, duque di Sermoneta. Antonio Starabba, marqués di

9s Olvidan este clima pacifista quienes juzguen a la ligera la advertencia de Salisbury al gobierno francés al plantearse la crisis de Fachoda, su «neutralidad sin fisuras» en el conflicto hispanonorteamericano, su discurso en la Primerose League en mayo de 1898 y el que pronunció el 9 de noviembre de ese mismo año. Inglaterra también se hallaba «rodeada» de naciones poderosas. La interpretación dada en España se vio motivada por el miedo al "peligro inglés", expresión usada por El Nuevo País varias veces en diciembre de 1898. La ha hecho suya Jover, José María: 1898: teoría y práctica de la redistribución colonial, Madrid, Fundación Universitaria Española 1979, pp. 15-18. La sigue DE LA TORRE, Rosario: Inglaterra y España en 1898, Madrid, Universidad Complutense1988, pp. 193-204. Como un aviso para los pacifistas ingleses, la he interpretado en 1898: Diplomacia y opinión, Madrid, Consejo Superior de Investigaciones Científicas, 1991, pp. 31, 54, 154-155, 159, 336-337 y 360.

96 Texto inglés anexo a 83/37 Ferrero-Blanc, 8 febrero, ASD CV 7/3 64. Salisbury dijo al embajador de Austria- Hungría, conde Deym, que las palabras de A. J. Balfour expresaban su pensamiento.

$9781 / 36$ Ferrero-Blanc, 7 febrero, ib. 63.

98 83/37 Ferrero-Blanc, 8 febrero, ib. 64. Sobre la opinión y su influencia Nigra-Blanc, 10 febrero, ib. 65. Este despacho se envió a Londres y Berlín, 11 febrero, ib. 67.

99 Esa fue la reacción de Blanc ante la noticia que sobre la posición del gobierno inglés y del suyo le dio el embajador Pasetti. Riservatissimo 7041/110 Blanc-Ferrero, 24 febrero, ib. 69. 
Rudinì, había sustituido a Crispi, que ya no volvería a presidir el gobierno. Rudinì se mantendría hasta junio de 1898. En la primavera de ese año, la crisis social provocó su caída. Fue sustituido por Luigi Gerolamo Pelloux, un general, ministro de la Guerra en su segundo gobierno.

Conocida en la asamblea nacional la existencia de la alianza con Rusia, la primera consecuencia fue el apoyo francés al Zar en la fase final de la guerra chino-japonesa. Gabriel Hanotaux había conseguido sacar a Francia de su aislamiento.

Según Ribot, presidente del consejo, la alianza permitía a Francia presentarse como una garantía para la paz. 25 años después de su derrota frente a Prusia y sin renunciar a los territorios que perdió en $1870^{100}$, recuperaba su lugar de gran potencia en el concierto europeo. Su objetivo inmediato era aislar a Alemania. Aunque parezca paradójico, la alianza con Rusia fue vista en Berlín como una prenda de paz. Esa apreciación explicaba su actitud ante Inglaterra en África y Asia.

La rivalidad, surgida por motivos comerciales, enraizaba en el sentimiento nacional de los ingleses. Afectaba a Italia el acercamiento franco-inglés. La animosidad existente había desaparecido. Las cuestiones pendientes entraban en vías de solución. Italia no debía creer que los litigios entre franceses a ingleses fueran insuperables. Un arreglo en la región del Nilo superior quitaba importancia a las cuestiones en el bajo Nilo, si el Reino Unido renunciaba a la continuidad territorial desde El Cabo hasta el Mediterráneo ${ }^{101}$. Italia no debía abandonar Kassala, pues se interpretaría como renuncia a su derecho a participar «nella risoluzione della maggiore delle questioni del Mediterraneo ${ }^{102}$.

Se habló entonces de un acuerdo entre Francia y España, pensando que habría sido la base de la operación diseñada para el Tuat.

Los gobiernos de Alexandre Ribot y de Léon Bourgeois se esforzaron en acortar distancias con Italia. La opinión, convencida de que los intereses franceses a italianos eran contrapuestos, condicionaba la negociación de las cuestiones

${ }^{100}$ Para acallar los comentarios de la opinión pública, el presidente de la República visitó en abril de 1896 la línea defensiva en la frontera con Alemania. El acto coincidió con las visitas de Guillermo II a Venecia y Viena. R. 1401/358 Tornielli-Caetani, París 22 abril 1896, DDI III/I (Roma, 1952) p. 55.

${ }^{101}$ Esta hipótesis no se cumplió. En 1898 los franceses hubieron de retirarse de Fachoda.. BATES, D. The Fashoda Incident of 1898: encounter on the Nile Oxford University Press, 1984. RENOUVIN, Pierre : La politique extérieure de Th. Delcassé (1898-1905) Paris, 1962, pp. 5 y 24. La documentación sobre este incidente, AAE «Papiers Delcassé», tomos 13 y 16. La reacción española, 1898: diplomacia y pacificación... pp. 312 y 335-337. Una reflexión sobre el alcance esta crisis, PABÓN, Jesús: Cambó. t. I, Barcelona, Alpha 1952, pp. 169-171 y El 98, acontecimiento internacional, Madrid, 1952, recogido en Días de ayer. Historias a bistoriadores, Barcelona, Alpha, 1963, pp. 139-195.

102 R. 920/240 Tornielli-Caetani, 12 marzo. El ministro de Italia en Buenos Aires creyó que la derrota de Massaua se debió a la presión de] partido militar sobre Crispi. Antonelli-Caetani, 13 de marzo, ib. 11. Había que conservar Kassala. T. Rudinì, Ricotti y Caetani-Baldissera, 14 marzo, DDI III/1 (Roma, 1952) pp. 4-9, 11 y 16. 
pendientes: los límites en África oriental, la denuncia del tratado italo-tunecino y las relaciones comerciales y marítimas entre las dos naciones.

La clase dirigente francesa no sentía antipatía hacia Italia. Las capas populares la veían como su enemiga natural, iniciadora de todas las combinaciones contra Francia. Ahora, la alianza con Rusia venía a rentabilizar los errores de Alemania, sobre todo, su enemistad con el Reino Unido ${ }^{103}$.

El acercamiento entre París y Londres acabó con una expectativa italiana: «la posizione che noi abbiamo lungamente sperato di vedere prendere per necessitá di cose dalla Inghilterra a fianco della Triplice Alleanza non sarà per lungo tempo più possibile e che l'opera nostra di servire di tratto di congiunzione fra Londra $\mathrm{e}$ Berlino rischia di esaurirsi nella ricerca dell'impossibile».

Desde 1891 habían pasado muchas cosas. Entonces se juzgó conveniente y posible la accesión del Reino Unido a la Triple. Ahora los acontecimientos amenazaban a Italia, que podría quedarse aislada y en inferioridad en el Mediterráneo, aunque Inglaterra necesitara todavía de la marina italiana para su hegemonía naval. Los puertos italianos tenían un gran valor ${ }^{104}$.

En abril, Léon Bourgeois reconoció que las relaciones franco-italianas habían mejorado gracias a la posición de alguno de los ministros del gobierno italiano en política internacional ${ }^{105}$.

Las cuestiones pendientes se arreglarían. Había buena voluntad en las conversaciones preliminares de Tornielli con Pierre Berthelot, ministro de Exteriores hasta el 28 de marzo de 1896. Bourgeois estaba en una excelente disposición. Había que superar el temor de la oposición parlamentaria debido a la pertenencia de Italia a la Triple Alianza ${ }^{106}$. Francia quería tener la seguridad de que Italia deseaba la paz y la amistad con ella ${ }^{107}$.

Mejoradas las relaciones con Francia, Italia propuso entonces a sus socios la continuación de la alianza, como estaba previsto, pero insistiendo en que se mantenía en vigor la declaración ministerial anexa al tratado y firmada también en $1882^{108}$.

${ }^{103}$ A su regreso de Berlín, Goluchowski tenía la impresión de que Alemania trataría de recomponer su relación con Inglaterra. El gobierno alemán aprobaba la política de amistad de Austria e Italia hacia el Reino Unido, aunque creía Guillermo II que Londres jamás accedería a firmar un acuerdo escrito. En cuanto a Rusia, el emperador dijo al canciller austriaco que trataría de desviar a Nicolás II hacia el extremo oriente, para alejarlo de las cuestiones europeas. T.c. 470 Lanza-Caetani, 14 marzo, DDI III/I... p. 15.

104 Tornielli juzgaba que para vencer en Etiopía se necesitaba las alianzas que pudieran establecerse con Francia e Inglaterra. Menelik II perdería su capacidad ofensiva. L. p. riservatissima Tornielli-di Rudin3, 13 marzo, ib. 12-14.

105 Días antes el gobierno di Rudinì hizo una declaración ante la Cámara. La renuncia a la política de expansión pareció a Guillermo II un acierto. Visita de Guillermo II a la embajada de Italia y comentario a la declaración. T.c. 510 Lanza-Caetani, 20 marzo 1896. DDI III/l... p. 24.

106 R. 1236/315 Tornielli-Caetani, 4 abril, ib. 37-40.

107 En la mañana del 1 de abril estuvo con Rudiní un enviado francés, Giacometti, que sugirió que Francia conocía el texto de] tratado de la Triple Alianza. L. p. Rudinì-Caetani, 1 abril, ib. 34.

108 Riservatissimo s.n. Caetani-Lanza y Nigra, 26 marzo 1896. La Nota ministerial: «Le Gouvernement Royal déclare que les stipulations du Traité secret conclu le 20 mai 1882 entre l' Italie, l' Allemagne

Hispania, LXV/2, núm. 220 (2005) 643-682 
Era un asunto vital para Roma ${ }^{109}$. En caso de una alianza entre el Reino Unido y Francia, Italia no podría, dada su posición geográfica, luchar contra las dos mayores potencias navales. Ningún gobierno podría empujar a Italia a esa aventura $^{110}$. Austria no objetaba la Nota de 1882, según manifestó Goluchowski ${ }^{111}$.

Caetani envió a los embajadores Costantino Nigra y Lanza un despacho idéntico fijando la posición de Italia para que la conocieran en Viena y Berlín. Era una redacción más extensa de la nota ministerial de 1882, subrayando que así su lealtad con sus aliados ${ }^{112}$. Marshall fue muy explícito con Lanza. Si se produjera un pacto entre Francia y el Reino Unido, como temía Italia, Alemania creía que sus intereses quedarían a salvo gracias al reajuste que ese hecho provocaría en Europa. Había más. La declaración italiana modificaría el contenido de la Triple Alianza, "giacchè la punta di ostilitá diretta a predominante contro la Russia, che tale interpretazione darebbe alla Triplice Alleanza, modificherebbe interamente il carettere essenzialmente impersonale di questo patto difensivo che mira agressioni eventuali, anzichè avversari individuali» ${ }^{113}$.

Expresados los sentimientos del gobierno italiano a sus aliados, el objetivo de Roma estaba cumplido ${ }^{114}$.

La noticia de la renovación de los pactos y la visita de Guillermo II al Rey Umberto en Venecia paralizaba la buena disposición de Bourgeois para llegar a un arreglo con Italia ${ }^{115}$. Según Tornielli, los pactos, como los instrumentos musicales, dependían de quienes los ejecutaban. Nada podría temerse por parte de

et l' Autriche-Hongrie ne pourront -comme il a été préalablement convenu- en aucun cas être envisagées comme étant dirigées contre l'Angleterre». Cumplimiento de la orden, R. s. n. Lanza-Caetani, 31 marzo, ib. 30 y 32 .

${ }^{109}$ El gobierno alemán consideraba superflua y hasta perjudicial la demanda italiana. T.c. s.n. Lanza-Caetani, 2 abril, ib. 35.

110 Con esta declaración leal al embajador B.H. Bülow, quiso di Rudinì cerrar la discusión, afirmando la fidelidad de Italia a sus aliados. Nada debía decirse al Reino Unido. T.c. s.n. RudinìNigra, 3 de Abril. El embajador en Viena creía que bastaba comunicar a Goluchowski confidencialmente esta declaración. T.c. y r. s.n. Nigra-Rudinì, 4 de abril, ib. 36-37.

111 T.c. s.n. Nigra-Rudini, 6 abril. Informe del embajador al ministro, L. conf. NigraCaetani, 9 abril, ib. 42 y $45-46$.

112 «Notre franchise doit, pour les deux Cabinets, être la preuve et le gage de notre scrupuleuse fidélité envers la Triple Alliance, telle qu'elle existe et que nous désirons la voir maintenue». T.c. s.n. Caetani-Nigra y Lanza, 26 abril. Goluchowski prefería que se reprodujera la nota de 1882 , añadiendo sólo «In quanto riguarda l'Italia». Y sin esperar respuesta. T.c. s.n. Nigra-Caetani, 27 abril, ib. 57-58.

113 T. s. n. Lanza-Caetani, 1 de mayo, ib. 62.

${ }_{114}$ T.c. s.n. Caetani-Nigra a Lanza, 30 mayo, ib. 73

115 En febrero de 1897, Léon Bourgeois visitó Italia. Durante su estancia en Roma habló con los principales ministros. Regresó con una excelente impresión. Bourgeois desconfiaba no solo de la pertenencia de Italia a la Triple Alianza, sino de su amistad con el Reino Unido. Cuando el 28 de junio de 1898 formó gobierno Eugène Brisson, Bourgeois ocupó la cartera de Instrucción Pública. El juicio del embajador italiano sobre ese gobierno, 639 Tornielli-Felice Napoleone Canevaro, 6 julio 1898, DDI III/III (Roma, 1962) pp. 2-4. 
Italia. Cuando no existen motivos para rescindir los compromisos, era normal, dijo Tornielli a Bourgeois, que se renovaran. La mejor forma de modificar la relación entre los aliados era acabar con la situación que creó el pacto ${ }^{16}$. Formado un nuevo ministerio, presidido por Felix Méline, Gabriel Hanotaux, ministro de Exteriores, reiteró su buena disposición ${ }^{117}$.

El presidente del consejo declaró en la Cámara italiana el 1 de julio su propósito de modificar el tratado ${ }^{118}$, pero aseguró a Bülow, el embajador alemán, que juzgaba el texto con las suficientes garantías y que, por esa razón, después de examinar la realidad política, decidió renovarlo. La frase que la agencia Stefani le atribuyó no fue pronunciada ${ }^{119}$.

En abril de 1896, el gobierno austriaco hizo una gestión para que el español renovara el acuerdo con Italia ${ }^{120}$. Goluchowski envió instrucciones al conde Viktor Dubsky, partidario declarado de la amistad entre los dos países. El duque de Tetuán le manifestó que no era el momento. Urgía a España pacificar Cuba. El gobierno sólo se aliaría con quien hiciese suya la causa de España frente a Estados Unidos ${ }^{121}$. Italia podría aprovechar su alianza con las otras dos potencias centrales para prestar a España ayuda diplomática ${ }^{122}$.

Informado de su conversación con di Rudinì por el conde de Benomar, embajador en Roma, el ministro de Estado dijo a Dubsky que España estaba dis-

116 Riservatissimo 13981355 Tormelli-Caetani, 16 abril 1896. Las palabras del embajador confirmaban la actitud amistosa y conciliadora de Italia hacia Francia. R. 13899/358 Caetani-Tornielli, 17 abril, DDI III/I (Roma, 1953) pp. 50-53.

117 R. 1555/398 y 1538/388 Tornielli-Caetani, 4 y 6 mayo, ib. 63-67. El posible nombramiento de Albert Billot para la embajada en Roma, Riservatissimo 1769/449 Tornielli-Caetani, 22 mayo, ib. 71-72.

${ }^{118}$ En Berlín el canciller Hohenlohe pidió explicaciones a Lanza. T.c. s.n. Lanza-Caetani, 2 julio, ib. 85 .

119 Tc. s.n. Caetani-Lanza, 3 julio. La mala impresión causada por esa confusión de la agencia Stefani, informe de Emerito Tkalac, intérprete en el ministerio de Asuntos Exteriores, redactado por orden de Caetani, y enviado a su sucesor Emilio Visconti Venosta el 3 dé agosto, ib. 87 y 100-104.

120 Sobre el contexto, «España y Europa durante la crisis cubana (1896-1897)», Consuelo Naranjo, Migue Ángel Samper-Puig y Luis Miguel García Mora (editores); La nación soñada. Cuba, Puerto Rico y Filipinas ante el 98 Aranjuez, Siete Calles, 1996, pp. 729-754. «España y las alianzas europeas en 1898», en Hispania (Madrid) 197 (1997) pp. 479-514. «El Mediteráneo y la diplomacia secreta. España a Italia en 1894», en Rassegna Storica del Risorgimento (Roma) LXXXIV/1V (1997) pp. 487-528. «Europa en 1898 y la guerra de Estados Unidos con España», en Boletín de la Real Academia de la Historia (Madrid) CXCV/II (1998) pp. 1-39. «El 98 español desde Roma», en Anales de Historia Contemporánea (Murcia) 14 (1998) pp. 95-117. «Il confronto europeo nel Mediterraneo oocidentale», en Rivista Storica Italiana (Torino)112/2 (2000) pp. 703-741. «España y el equilibrio mediterráneo (1890-1891)», en Hispania (Madrid) 208 (2001) pp. 149-183.

${ }^{121}$ Una detallada información sobre la situación en Cuba, Promemoria, 8 diciembre 1895, ASD SP P 701895.

${ }^{122}$ Dubsky y Drummond Wolff creían que, aunque el convenio con Italia de nada había servido, había impedido que España se echara en brazos de Francia, cuya fuerza se multiplicaría teniendo sus fronteras del Sur seguras gracias a la amistad con Madrid. Renzis-Caetani, Madrid 24 abril 1896, DDI III/I (Roma, 1963) pp. 55-56.

Hispania, LXV/2, núm. 220 (2005) 643-682 
puesta a renovar el acuerdo, pero comunicaría a Italia que la situación había variado. Su preocupación estaba en las Antillas. Subordinaba sus compromisos internacionales al objetivo de mantener su soberanía en Cuba y Puerto Rico. Un acuerdo con la Triple Alianza, a través de Italia, sobre el Mediterráneo, le ataría las manos.

Más allá de la solidaridad diplomática, el gobierno español quería tener la seguridad de que, si hubiera de combatir con la norteamericana, la escuadra eśpañola no iría sola, sino acompañada por sus aliados. Si se produjera esa situación, acudiría a Italia y al Reino Unido, con quienes la unían tantos intereses. Convenía a ambas una España fuerte y no desmembrada.

Si no tuviera eco esa solicitud, dijo Tetuán, haremos a otros «todas las concesiones que juzguemos necesarias para obtener su apoyo material. El naufrago se agarra a la tabla de salvación sin mirar la mano de quien se la ofrece». La contrapartida sería la oferta de puertos en el Mediterráneo a cambio de barcos para poder resistir a la arrogancia norteamericana. El tono pretendía que el embajador de Italia marchara convencido de que no sería difícil para España un pacto con Rusia y Francia. Era, por tanto, según Francesco De Renzis, ilusorio pensar que España renovaría el acuerdo «senza insistere sulle garanzie della possessione di Cuba» ${ }^{123}$.

Benomar dijo a Onorato Caetani que el pacto debía incluir la garantía sobre Cuba y alguna forma de adhesión del Reino Unido al mismo ${ }^{124}$.

Drummond Wolff, antes de viajar a Londres para consultar a Salisbury, manifestó a la Reina Regente que ninguna potencia garantizaría la pertenencia de Cuba a España. Habría que conformarse con la cooperación diplomática. Nadie se arriesgaría a una guerra con Estados Unidos ${ }^{125}$. Esa fue también la posición de Austria ${ }^{126}$.

El 26 de julio el conde de Benomar dijo al nuevo ministro de Exteriores, Emidio Visconti Venosta, que España, no pudiendo incluir una garantía sobre Cuba y faltando el consentimiento del partido liberal, no renovaría el pacto, pero, mientras estuviese el partido conservador en el poder, «la sua politica

\footnotetext{
123 En esos momentos Drummond Wolff vigilaba los pasos del duque de Tetuán para evitar un acercamiento a Francia. Dubsky defendía la renovación del acuerdo. Alemania se mostraba indiferente, porque su embajador desconfiaba de Cánovas. Riservatissimo 280/90 Renzis-Caetani, de abril, ib. 59-61.

${ }^{124}$ Caetani quiso explorar la posición de sus dos aliados, Austria y Alemania. T.c. s.n. CaetaniNigra y Lanza, 1 mayo, ib. 61.

125 «Nè alla Triplice Alleanza nè all' Inghilterra certamente converrà garantire alla Spagna il possedimento di una colonia a metà perduta, con rischio di un conflitto con gli Stati Uniti d'America del Nord». Renzis pensaba que Francia tampoco habría ofrecido eso. Sólo podría esperarse «un apoggio morale verso gli Stati Uniti», argumentando que la integridad territorial de España era importante para el equilibrio europeo. Riservatissimo 293/93 Renzis-Caetani, 2 mayo, ib. 62-63.

126 Conversación con Goluchowski. T. conf. Nigra-Caetani, 13 mayo. Amplió esta noticia en Conf. 1292/393, 21 mayo, ib. 69-71.
} 
verso l'Italia e verso i suoi alleati si ispirerà alle stesse condizioni come se il patto fosse stato rinnovato» 127 .

La negociación duró varios meses y concluyó sin éxito. España trasladaba el horizonte de su política internacional a sus territorios ultramarinos. Sabía que en el Mediterráneo occidental no estaba sola. Para Cuba buscó alianzas sin lograrlo. Le prometieron un apoyo poco eficaz.

La opinión no consentía a los gobiernos europeos compromisos que pudieran llevarlos a una guerra ${ }^{128}$. La actitud de los países de la Triple Alianza, del Reino Unido y, luego, de Francia, probaba, de manera indirecta, que a esas alturas, pasado más de un año de guerra en Cuba, nadie dudaba que Estados Unidos terminaría participando en ella y contra España ${ }^{129}$. Se comprende ahora que España, como anunció el ministro de Estado a Dubsky, acudiera esos meses a la mediación de las potencias, la única «tabla de salvación» que le habían ofrecido.

\section{EsPaÑa ANTE EsTados UNIDOS}

A comienzos de 1896 giró la política en Cuba. El comité de Relaciones Exteriores del Senado de Estados Unidos pedía que la guerra respetara las normas que rigen en las naciones civilizadas y cristianas. Se mostraba dispuesto a reconocer como beligerantes a los insurgentes cubanos. Como sucedió a otros gobiernos europeos, el conservador presidido por Cánovas se hallaba en la encrucijada: contar con el orgullo de un país, que no aceptaba ser derrotado, o negociar con quienes eran acusados de delito de lesa patria. Mientras Martínez Campos fue capitán general de Cuba, los independentistas lucharon respetando al adversario. El nombramiento de Valeriano Weyler como comandante en jefe y primera autoridad de la Isla, «choisi á cause de sa brutalité», pondría en marcha la espiral represión-violencia ${ }^{130}$. Se inició una "guerra terrorista»131, cuya expresión estratégica sería la concentración de la población ${ }^{132}$.

127 Despacho s.n. Visconti-Renzis, 26 julio, ib. 92-93. Se envió copia a Costantino Nigra.

128 «.. in una situazione tanto mutata, che vedi gli amici litigare tra loro ed i nemici d'ieri accostarsi oggi, il fragile accordo del 1887, nato in atmosfera di fermezza e stabilitá di alleanze, si dissolve nella nuova situazione creata dalla fluidità dei rapporti internazionali e viene meno». CURATO, Federico: La questione marocchina a gli accori mediterranei halo-spagnuoli del 1887 e 1891, volume secondo... Milano, Edizioni di Comunità, 1964, p. 601.

129 Hay que ampliar, pues, la conclusión de Curato. «L'unione italo-spagnuola è l'unione di due deboli contro il più forte, ma nessuno di due deboli è interessato all'independenza del Marocco per se stesso, ognuno nutre delle aspirazioni più vaste (La Spagna) o meno vaste (L'Italia) e queste aspirazioni costituiscono il limite del patto. Le due potenze unite sono rivali, concurrenti, gelose l'una dell'altra, ed ognuna guarda con sospetto qualsiasi iniziativa dell'altra». F. Curato, ib. 597.

${ }^{130}$ El embajador francés comentó a Cánovas los efectos negativos de esa decisión y de la campaña de la prensa española contra Estados Unidos. 16 Reverseaux-Berthelot, 2 de febrero y t.c. 16 1 de marzo, AAE CP Espagne 92876 y 129. La justificación de su labor, WEYLER, Valeriano: Mi

Hispania, LXV/2, núm. 220 (2005) 643-682 
Los insurgentes iniciaron una guerra de destrucción de la isla. Incendiaban pueblos y pequeñas ciudades. Máximo Gómez declaró su voluntad de establecer la República Cubana sobre las ruinas de la Isla. En Pinar del Río, Antonio Maceo destruyó la cosecha de tabaco. Los abusos cometidos por españoles crearon problemas con Estados Unidos ${ }^{133}$. Valeriano Weyler no pudo cumplir su promesa de que podría hacerse la zafra, al menos en las proximidades de La Habana ${ }^{134}$.

Cleveland envió al Congreso la documentación relativa a la insurrección cubana desde febrero de 1895 . Iba precedida de la proclama presidencial recordando los deberes que la neutralidad imponía a los ciudadanos norteamericanos.

El sentimiento de americanismo y el deseo de controlar el comercio del tabaco y del azúcar presionaban sobre los congresistas ${ }^{135}$. Los proponentes y los que apoyaban esas resoluciones sabían que sus electores eran hostiles a España ${ }^{136}$.

Estaba Cleveland dispuesto a cumplir sus deberes internacionales y a respetar la neutralidad. España lo sabía y lo agradecía. Ni la mayoría, a favor de los buenos oficios, ni la minoría que pedía el reconocimiento de la independencia, habían conseguido aprobar una resolución. El senado se limitó a decir que pasaran al orden del día ${ }^{137}$.

mando en Cuba (10 de febrero de 1896 a 31 de octubre de 1897). Historia militar y política de la última guerra separatista durante dicho mando, 5 tomos, Madrid, 1910-1911.

131 Sobre "guerra terrorista» y la conducta de Weyler, THOMAs, Hugt: Cuba, la lucha por la libertad, tomo I, Barcelona-México, Ediciones Grijalbo S. A.,1973, pp. 419 y 429-441. Un análisis de los diferentes aspectos del «terror» como estrategia, en la aportación de Eduardo GONZÁLEz CALLEJA, en la obra coordinada por él, Políticas del miedo. Un balance del terrorismo en Europa, Madrid, Biblioteca Nueva, 2002, pp. 35-142.

132 Como medida militar, la propuso Martínez Campos a Cánovas en junio de 1895 , indicando que él no la aplicaría. Se ha acusado a Casas, un sacerdote católico, de haber propuesto reconcentrar a los campesinos para privar de auxilios a los rebeldes. Juan Bautista CASAS, La guerra separatista de Cuba, Madrid, 1896. RoIG, Ernesto: Dos guerras cubanas. Ensayo de revalorización, La Habana, 1945, pp. 62-63. ROBLES, Cristóbal: «Guerra y población civil: los reconcentrados», en «La Marina ante el 98 (II). Génesis y desarrollo de un conflicto", Cuadernos Monográficos del Instituto de Historia y de Cultura Naval (Madrid)11 (1990) pp. 21-44.

133 Una columna sorprendió a unos 40 rebeldes en la hacienda de la familia Delgado, cerca de Bainoa. Tras desalojar a los rebeldes, los soldados llevaron al hijo del dueño y a los trabajadores ante el general Melquizo. Este los entregó a un pelotón de voluntarios para que los fusilaran. Se salvó el Dr. Delgado, el hijo del dueño, a quien dieron por muerto, a pesar de que lo remataron con tres machetazos. Conducido a La Habana, dado que era ciudadano norteamericano, el cónsul de Estados Unidos denunció el caso ante Weyler. Conf. 110/34 Marefoschi-Caetani, 15 marzo. ASD SP P 711896.

134 85/27 Marefoschi-Caetani, 27 febrero y 20 marzo, ib. 711896.

135 Sobre este aspecto del problema cubano, «La lucha de los independentistas cubanos y las relaciones de España con los Estados Unidos», en Hispania (Madrid) 174 (1990) pp. 159-202.

$136 \mathrm{El}$ ataque al consulado de Estados Unidos en Barcelona revelaba la tensión creada por lo dicho en el Congreso norteamericano. Informe del cónsul en Barcelona, 269/34 Stella-Caetani, 3 marzo. Las manifestaciones contra la legación norteamericana en Madrid, t. c. 140/48 RenzisCaetani, 4 marzo, ib. 1896.

137 197/56 Fava-Caetani, Washington 29 febrero. El ambiente en Madrid, 138/46 RenzisCaetani, 2 marzo, ASD SP P 711896. 
El diputado Hitt, presidente del Committee on Foreign Affairs, presentó el 12 de marzo una proposición. El Congreso opinaba que había un estado de guerra en Cuba. Los contendientes tenían derecho a ser considerados beligerantes. Estados Unidos observaría una estricta neutralidad. El Congreso lamentaba la destrucción de vidas y propiedades y «juzgando que la única solución permanente del conflicto, en interés del pueblo de Cuba y de las naciones, sería el establecimiento de un gobierno elegido por el pueblo de Cuba» el Congreso estaba convencido de que el Gobierno de Estados Unidos debía ejercer sus buenos oficios y su influencia amistosa para alcanzar ese objetivo.

Estados Unidos no había intervenido jamás en conflictos entre a gobiernos europeos y sus colonias en este continente, pero las estrechísimas relaciones entre el pueblo de Estados Unidos y el de Cuba, como resultado de su proximidad y de la importancia del comercio entre los dos pueblos, llevaban a denunciar que la guerra causaba tales pérdidas al pueblo de los Estados Unidos que «el Congreso opina que el gobierno de los Estados Unidos debe estar preparado para proteger los legítimos intereses de los americanos incluso mediante la intervención, si fuera necesaria».

Su resolución fue aprobada por 263 votos contra 17. Inmediatamente fue remitida al senado. Su Committee on Foreign Affairs aprobó un texto más breve, pero mas enérgico. El objetivo de los oficios amistosos del presidente era el reconocimiento de la independencia de Cuba. Se votaría una Joint Resolution el 9 de marzo ${ }^{138}$. En España se temía que el reconocimiento de la beligerancia conduciría a la independencia de Cuba, salvo que Cleveland la vetara ${ }^{139}$.

Ante un posible conflicto de poderes ${ }^{140}$, el 23 de marzo Platt presentó su resolución: el senado manifestaba el deseo de que Cuba fuera pronto una República independiente. Y para eso, el presidente ofrecería sus buenos oficios a España. La propuesta fue remitida al comité de relaciones exteriores. El senador Milly invitó a Cleveland a pedir a España la autonomía de Cuba y, en caso de rechazo, Estados Unidos debería apoderarse de la isla ${ }^{141}$. ¿Había enviado ya Estados Unidos a su ministro en Madrid propuestas de mediación para una solución de la cuestión cubana? ${ }^{142}$. No había nada concreto aún. Habría que esperar a que se calmaran los ánimos, pero se trabajaba en esta dirección: otor-

\footnotetext{
138 Oficiosamente la Casa Blanca dijo que Cleveland no reconocería la beligerancia a los cubanos. «Cuban Belligerency. The President not yet Fully Prepared to Recognize it», The Evening Star, march 4, 1896.

139 165/55 Renzis-Caetani, 13 de marzo de 1896, ASD SP P 711896.

${ }^{140}$ La Cámara de Representantes votó una resolución que sustituía la dei Senado reconociendo a los cubanos la beligerancia. Varios senadores advirtieron que esa era una prerrogativa presidencial. El Congreso no podía usurpar las furicione del ejecutivo.

141 The New York Herald calificó la proposición «an act of piracy». 254/76 Fava-Caetani, 23 marzo, ASD SP P 711896.

${ }_{142}$ Se desmintió la noticia en Washington. Se supo luego que lo publicado era un resumen de la nota de Fish en 1868.
}

Hispania, LXV/2, núm. 220 (2005) 643-682 
gar a Cuba una autonomía administrativa, con la creación de un Consejo General, que pudiera elaborar su presupuesto, sancionado luego por las Cortes, donde podrían defenderlo los representantes cubanos.

Estados Unidos ejercería sus buenos oficios ante los rebeldes para que aceptaran la solución y depusieran las armas. Mientras, Washington establecería una pausa a su acción diplomática, actuando de manera conciliadora, sin dejar de usar como argumento los grandes intereses de sus ciudadanos en Cuba ${ }^{143}$.

Parte de la propuesta española quedó recogida en el Discurso de la Coro$n a^{144}$. El 11 de mayo se denunció a los rebeldes, cuyos jefes eran «extranjeros o gentes de color», que no deseaban mejoras políticas y administrativas, sino la independencia. Por eso se alzaron cuando iban a ponerse en práctica esas medidas. Con la paz, Cuba y Puerto Rico tendrían una «personalidad administrativa y económica, de carácter local, pero que haga expedita la intervención total del país en sus negocios peculiares, bien que manteniendo intactos los derechos de la soberanía e intactas las condiciones indispensables de su subsistencia». Estados Unidos, pese a las presiones que había recibido su presidente, mantuvo la «leal amistad», que había existido siempre entre los dos pueblos ${ }^{145}$.

\section{FRANCIA, ¿ALIADA DE ESPAÑa?}

La ayuda de Francia a España en este conflicto isustituiría sus acuerdos mediterráneos con Italia, firmados en 1887 y renovados una vez en 1891? ¿Negociaban Francia y España? Los embajadores de Alemania, Austria-Hungría a Inglaterra así lo creían. Era una operación secretísima pero conocida en el Foreign Office. El ministro alemán en Tánger lo había notificado al embajador Radowitz.

Se disimulaba las frecuentes visitas del embajador francés al ministro de Estado diciendo que negociaban la aplicación a los ciudadanos franceses de la convención con Estados Unidos de 1877. Se había pedido también una rebaja de la tarifa sobre los productos franceses que entraban en Cuba. Ni estos dos motivos ni la negociación de un préstamo de casi 1000 millones eran una explicación satisfactoria.

¿Se trataba más bien de un acuerdo sobre Marruecos? ¿Con qué fin? Reverseaux viajo a París, donde había tensiones entre el parlamento y el gobierno.

\footnotetext{
${ }_{143}$ De modo estrictamente confidencial, Dupuy de Lome, ministro de España en Washington, dijo a Fava que existía un permanente y activo intercambio de puntos de vista con R. Olney para concertar un arreglo que pusiera fin a la guerra. 282183 Fava-Caetani, 15 abril. Sobre el reconocimiento de beligerancia a los insurgentes, 270/79 Fava-Caetani, 7 de abril ASD SP P 711896.

144 R. 256180 Renzis-Caetani, 22 abril, ib. 711896.

145 «Discurso... en la Solemne Apertura de las Cortes», suplemento a la Gaceta de Madrid, 11 de Mayo de 1896.
}

Hispania, LXV/2, núm. 220 (2005) 643-682 
José Elduayen, nombrado ministro de Estado el 19 de enero ${ }^{146}$, dimitió y regresó el duque de Tetuán ${ }^{147}$.

Se rumoreaba una propuesta de Francia a España. Se negó pero era creíble, porque España estaba con el «agua al cuello» y necesitaba colocar 25 millones de bonos cubanos. La situación ruinosa del transporte ferroviario en España forzaba a los franceses a pedir una prolongación de las concesiones para resarcirse cuando se relanzara la actividad económica.

Los valores españoles habían aumentado en la Bolsa de París y se rebajó el tipo de cambio. Ninguno de los dos hechos tenían un alcance meramente económico. Cánovas estaba pidiendo a Sagasta un consenso patriótico para cerrar la operación ${ }^{148}$. Los ataques a la legación de Estados Unidos en Madrid y a su consulado en Barcelona suponían una presión sobre el gobierno conservador.

A su regreso de París, el embajador de Francia estuvo con Cánovas. La entrevista fue larga. El presidente del consejo comentó a una persona de confianza que el acuerdo financiero estaba asegurado a cambio de concesiones en los ferrocarriles, pero podría «jurar» que no se había pronunciado la palabra alianza y que España conservaba su total libertad de acción en política internacional.

Aunque fuera verdad, el embajador de Francia actuaba como si quisiera hacer creer lo contrario, pues, aunque no existiera acuerdo, pensar que lo había beneficiaba a su gobierno. Para reforzar esa apariencia había solicitado una audiencia con la Reina ${ }^{149}$.

Cánovas se consideraba en condiciones para afrontar el futuro. La banca de París asumía los bonos de Cuba que quedaban sin colocar y los situaba en Bolsa. Se comprometía a llegar hasta 1000 millones de préstamo, una vez arreglada la cuestión cubana. Se daría facilidades al comercio francés para las certificaciones de origen. Se prometió tratar a los ciudadanos franceses como a los norteamericanos, protegidos por la convención de $1876^{150}$ y aplicar a los franceses el protocolo his-

${ }^{146}$ Salió el duque de Tetuán, a quien se vinculaba con el general Martínez Campos. La crisis ministerial se redujo a la entrada de José Elduayen en el ministerio de Estado. 49/16 RenzisCaetani, 20 enero, ASD SP P 711896

${ }_{147}$ R. e c. $117 / 37$ Renzis-Caetani, 22 febrero 1896, enviado impreso el 19 de marzo a las embajadas en Viena, París, Berlín y Londres y a la legación en Tánger, ib. 711896.

148 121/39 Renzis-Caetani, 26 febrero 1896, enviado impreso el 19 de marzo a las embajadas en Viena París, Berlín y Londres y a la legación en Tánger, ib. 711896.

149 Para Renzis la estrategia de su colega francés era una «attività morbosa». Despacho escrito personalmente por Renzis, 137/45, 2 marzo 1896, enviado impreso el 19 de marzo a las embajadas en Viena París, Berlín y Londres y a la legación en Tánger, ib. 711896.

${ }^{150}$ El embajador en París recogía un comentario de Gabriel Hanotaux sobre el riesgo de que un sumarísimo condenase a muerte y fuesen pasados por las arrnas algunos franceses que combatían con los cubanos Conf. 133 Mandas-Tetuán, 19 mayo 1896. España estaba dispuesta a examinar caso por caso. Se ordenó a Weyler, Gobernador General de Cuba, que no se cumpliera ninguna sentencia sin llevar su aprobación. Real Orden Tetuán-Mandas, 28 mayo, AMAE H 2416. Hubo una primer t.c. del ministro de la Guerra, Marcelo Azcárraga, que sirvió de precedente a un Real 
pano-norteamericano de $1877^{151}$. Se ampliarían las concesiones ferroviarias mediante una ley, que se presentaría enseguida a las Cortes ${ }^{152}$.

Cuando los italianos eran derrotados en Abisinia y los ingleses y egipcios avanzaban en Sudán, la prensa española abrió un debate sobre la posición internacional de España. La mayoría estaba a favor de abandonar el aislamiento, pero la opinión se dividía a la hora de elegir aliados. Estados Unidos era demasiado fuerte para enfrentarse solos a su poderío. Era la primera consecuencia de la guerra en Cuba.

Entre la prudencia, como aconsejaba Juan Valera ${ }^{153}$ y el compromiso con otras potencias, la conveniencia de España estaba en continuar fuera de las alianzas. Para ella no eran viables. No podía aliarse con Alemania, pues se oponían los republicanos, que tacharían esa decisión como sometimiento de los intereses de la nación a los de la dinastía. No aceptarían una con Francia los que juzgaban sus instituciones una república atea y sometida a la masonería. Pactar con Inglaterra sería desconocer que sus gobiernos siempre buscan el propio interés olvidando el de sus amigos.

Frente a esa definición de La Época, defendían El Imparcial y El Heraldo una posición más abierta. El primero subrayaba el poder militar español y apostaba por esperar sin adelantarse a las demandas de los otros. El segundo, ponía el ejemplo de la alianza franco-rusa. Las diferencias políticas no eran obstáculo para coincidir en el plano internacional. El Correo sugería aproximarse al Reino Unido y sumar las fuerzas navales de ambos. El País recordaba los intereses comunes con Francia en Marruecos. La Correspondencia de España y El Liberal apostaban por alianzas con las repúblicas de la América hispana, siendo un lazo

Decreto del 11 de noviembre de 1897, autorizando a los Gobernadores Generales de Cuba la concesión del indulto. Colección legislativa de España 162 (1897), Madrid, 1906, pp. 430-431.

${ }^{151}$ En él se clarificaba el contenido del artículo 7 del Tratado de amistad, límites y navegación firmado entre los dos gobiernos el 27 de octubre de 1795. Sobre los problemas que causó este convenio al tener que aplicarlo a los cubanos nacionalizados norteamericanos, «La oposición al activismo independentista cubano» en Hispania (Madrid)168 (1988) pp. 227-288.

152 «L'ambasciatore di Francia non è pienamente soddisfatto di quanto ha concluso. La Francia non chiede per ora impegni scritti di alleanza. Ció verrà fatalmente quantunque gli spiriti siano qui da ció alieni di pregiudiziale». 140/48 Renzis-Catalani, 4 marzo 1896, ASD SP P 71 1896. El texto fue cifrado. Se envió impreso el 19 de marzo a las embajadas en Viena París, Berlín y Londres y a la legación en Tánger.

153 «Una nación aislada como lo está España, con menos de la cuarta parte de habitantes que tienen los Estados Unidos y con muchísimos menos recursos pecuniarios para comprar o fabricar los costosísimos medios de destrucción que hoy se emplean, incurriría en un heroico delirio y cometería un acto de temeridad... pidiéndoles con sobrada energía satisfacción de una injuria que, en mi sentir, se puede por ahora disimular sin deshonra. Tenemos también el handicap del aislamiento. Cuantos gobiernos y cuantos partidos han estado en el poder desde hace muchos años y han propendido al aislamiento, movidos por una prudencia mal entendida y por un concepto equivocado y mezquino de la importancia y del valor de la nación, cuyos destinos dirigían». J. Valera, artículo publicado en Diario de Cádiz, 13 marzo 1896, cit. por BARAJA, Manuel: La Guerra de Independencia Cubana a través del Diario de Cádiz 1895-1898 Cádiz, Universidad de Cádiz, 1979, pp. 289-290. 
entre ellas y Europa, pero sin precipitarse para aceptar aliados. El Tiempo criticaba el aislamiento sin sugerir propuestas.

El embajador inglés, para atraerse a España, hablaba de una alianza con Francia ${ }^{154}$. Alemania insinuó su disposición a ejercer sus buenos oficios en Washington si se reanudaba la negociación comercial pendiente. Francia ofrecía su ayuda económica en los mercados financieros y política en el control de los refugiados republicanos y carlistas 155 .

La polémica en la prensa planteaba algunas preguntas. ¿Había sido idea de un periodista o indicación de personajes políticos para preparar una situación nueva? ¿Se limitaría a sacar provecho del movimiento de simpatía hacia España surgido en las repúblicas americanas?

En la Triple Alianza, Alemania juzgaba una carga la presencia de España. A Austria-Hungría no le interesaba. Italia no se había preocupado de alentar una amistad ofrecida en términos imprecisos y sin descender al terreno de los hechos.

No podría unirse España con Inglaterra, pues aunque Londres no lo rechazara, los españoles no soportarían establecer vínculos con quien ocupa Gibraltar. ¿Francia? Había ofertas del embajador francés, pero sin éxito.

¿Modificaban las necesidades recientes la postura de Cánovas? La Reina Regente temía la propaganda republicana y se opondrían a una alianza con Francia. ¿Podría frenarla, si se lo impusiera una opinión, movilizada por la prensa? A favor de esa alianza con Francia estaba también la intensificación de las relaciones financieras entre los dos países. El gobierno de París se apresuraba a sumar aliados, aunque lo fueran sólo en apariencia.

No era España una "cantidad despreciable». Tenía un ejército aguerrido y con una tradición muy estimable. La geografía sustituía la insuficiencia de su marina de guerra y le permitía hacer oír su voz en las cuestiones del Mediterráneo. Y todo esto sucedía cuando crecía la certeza de que Cuba estaba perdida. Incluso venciendo la insurrección, habría que darle una autonomía que llevaría por sus propios pasos a la independencia ${ }^{156}$.

\section{0. «UNN ÉLAN UNANIME» A FAVOR DE ESPAÑA}

Cuba era el escenario de una guerra que ponía a prueba la identidad hispana, arruinaba su hacienda y comprometía su futuro ${ }^{157}$. $\mathrm{Al}$ percibir así y casi de

\footnotetext{
154 «C'était un prétexte pour laisser entendre que le concours de l'Angleterre pourrait être accordé dans certaines conditions, c'est-à-dire, certaines complaissances dans l'action brytannique au Maroc».

15548 Reverseaux-Berthelot, 25 marzo, AAE CP Espagne 928 202-205.

156 187/62 Renzis-Caetani, 25 marzo 1896, escrito personalmente, ASD SP P 711896 y CV 9/6.

157 «El azote cruel de la guerra está desolando y empobreciendo hasta la ruina uno de nuestros territorios, el de la Isla de Cuba. Semejante lucha, que reviste caracteres de lucha mortal, reclama además esfuerzos, que son superiores a nuestro debilitado vigor nacional, y apura y empeña a nuestro común erario, preparando mayores conflictos venideros en el orden económico del país». "Carta 
modo espontáneo el conflicto, se negaba su carácter colonial y se daba legitimidad a quienes combatían por su independencia y a quienes proponían negociar sobre ella ${ }^{158}$. La única salida era «la separación absoluta»159.

No estaba claro cómo acabaría la guerra en Cuba. España recibió ayuda hasta de la Santa Sede ${ }^{160}$ En 1896 algunos políticos aconsejaban negociar, disimulando lo que pudiera haber de humillante o discutible en las propuestas que venían de Washington. Cuando llegó la oferta de R. Olney, aconsejaron Segismundo Moret y Francisco Silvela aceptarla, asociando a Francia a Inglaterra a la mediación con los rebeldes. Se salvaba así el amor propio de los españoles. El embajador francés se limitó a escuchar y acusó a su colega Drummond Wolff de haber sido menos discreto, esperando cobrarse el favor en Marrue$\cos ^{161}$. Pocos días más tarde, el embajador viajaba a Londres para recibir instrucciones de Salisbury. Allí coincidió con el ministro inglés en Tánger ${ }^{162}$.

Para el nuevo embajador de Italia en Madrid, España vivía encerrada en sus propios límites y sin relaciones políticas con el resto de Europa ${ }^{163}$. La guerra se había activado en Cuba. Existía siempre la posibilidad de un incidente con Estados Unidos, que provocara una crisis y que llevara a la guerra ${ }^{164}$.

del Prelado mandando celebrar un triduo y rogativas públicas en las parroquias!.., 16 de abril», en Boletín Eclesiástico de Zamora 6 (18 de abril de 1896) pp. 89-92.

158 «Mediación, sí, pero sólo eso». El delegado del Partido Revolucionario Cubano en Nueva York aprobaba la conducta del delegado en París, que se había «mantenido dentro del sentimiento revolucionario y de lo mandado por los poderes de la República, al manifestar que nada podía tratar si no sobre la base de la independencia de Cuba. Esta es la única solución». Cualquier propuesta debería someterse a «esa condición forzosa a ineludible». Estrada-Betances, 1 junio 1896. El conflicto era entre España y Cuba, no de España con Estados Unidos. Estrada-Betances, 13 octubre 1896 y 9 febrero 1897. Correspondencia Diplomática de la Delegación Cubana en Nueva York durante la guerra de la Independencia de 1895 a 1898, tomo I, La Habana 1943, pp. 44, 87 y 111.

159 Respuesta de Estrada a la proposición que el presidente de la República Dominicana, Ulises Heureux, le presentó a través de Jaime Vidal. Estrada-Vidal, 9 junio, ib. p. 53.

160 Mientras se luchaba para conseguir el reconocimiento de la condición de beligerantes a los cubanos, Gonzalo de Quesada informaba a Tomás Estrada el 24 de marzo de 1896, sobre las gestiones reservadas de la Iglesia Católica ante el presidente Cleveland, ib. V, La Habana, 1946, p. 52. Sobre la conducta de la Santa Sede, vid. «1898: La batalla por la paz. La mediación de León XIII entre España y los Estados Unidos», en Revista de Indias (Madrid) 177 (1986) pp. 247-289. Manuel MAZA MiQUel Entre la ideología y la compasión. Guerra y paz en Cuba, 1895-1903, Santo Domingo, Instituto Pedro Bono, 1997. Su tesis defendida en la Georgetwn University en 1986 fue «Between Ideology and Compassion. The Cuban Insurrection of 1895-1898, through the private correspondence of Cuba's two prelates whit the Holy See». PAzos, Antón: «América Latina y el Caribe hacia 1898 según la diplomacia vaticana», en Hispania Sacra (Madrid) 99 (1997) 543-567.

16159 H. de Reverseaux-Léon Bourgeois, 17 de abril, AAE CP Espagne 928 242-243

${ }_{162} \mathrm{H}$. Drummond Wolff «est un agité partisan forcené de la marche en avant et confiant dans l'audace de son pays, qu'il têve de voir installé en maître dans l'empire chérifien». 67 ReverseauxHanotaux, 1 de mayo, ib. 261.

${ }^{163}$ Como pórtico a una extensa exposición sobre la situación política y financiera, la guerra en Cuba y la postura de los liberales, el embajador se excusaba de tener que reducir su informe a esos aspectos de «escaso interés». R. 3971123 Renzis-Visconti, 11 mayo 1896, ASD SP P 71 1896-1897.

164 172/43 y 191/47 Marefoschi-Caetani, 5 y 20 mayo 1896 ASD SP P 711896.

Hispania, LXV/2, núm. 220 (2005) 643-682 
El gobierno francés se sentía moralmente obligado a secundar «un élan unanime» de su opinión pública. Impedía el embarque de armas para los independentistas y había autorizado la cotización en la Bolsa de París de $320 \mathrm{mi}$ llones de pesetas en billetes de Cuba. España, que podría necesitar un empréstito, debería corresponder.

En una declaración leída en la Cámara, Léon Bourgeois planteó la cuestión de Egipto en el marco de una posible reacción de los musulmanes contra los europeos. Eso podría crear serios problemas no sólo a las potencias con territorios vecinos al valle del Nilo, sino a las que tenían posesiones coloniales con población musulmana. Esa referencia incluía a Turquía; a la que se consideraba integrada en el concierto europeo.

Egipto debía permanecer como un asunto europeo. Francia no desconocía la labor civilizadora de Inglaterra, pero recordaba: «Il est d'intérêt général que l'avenir de l'Egypte... soit assuré dans des conditions qu'un examen impartial des puissances doit pouvoir permettre de déterminer équitablement» ${ }^{165}$.

Hubo una entrevista entre Burgeois, ministro de Asuntos Exteriores, y el embajador de Italia en París. Desmentía su elogio del nuevo clima entre los dos pueblos la actitud de la prensa sobre al guerra de Etiopía. Se presentaba a los enemigos de Italia como gente civilizada para agradar a Rusia. Este desencuentro de una antigua amistad entre los dos pueblos con la opinión escrita turbaba las relaciones mutuas, pese a la coincidencia de intereses.

El embajador Tornielli, tal como hizo con Pierre Berthelot, el anterior ministro de Asuntos Exteriores, recordó los asuntos pendientes: las zonas de contacto en África, las cuestiones comerciales en Europa y el tratado de comercio italo-tunecino.

En todas cabía una negociación conjunta que estableciera justas compensaciones donde los intereses fueran opuestos. La campaña de prensa quitó calma a las conversaciones. Tornielli, que acababa de regresar de Roma, aseguró que el nuevo gobierno italiano tenía los mejores propósitos para llegar a un arreglo, que acercara de forma estable a las dos naciones.

Tal como estaban, las relaciones comerciales perjudicaban los intereses de cada una de las partes. Explicaban esta anomalía razones políticas y la situación parlamentaria de Francia. Un sector de la Asamblea Nacional se resistía a llegar a un convenio mientras Italia perteneciera a la Triple Alianza.

El marqués di Rudinì deseaba un acuerdo comercial y, a partir de él, mejorar las relaciones, pues, como sucedía a Bourgeois, también tenía que presentar a su parlamento compensaciones a cambio de la renuncia a las ventajas que hasta entonces tenían los italianos en Túnez ${ }^{166}$.

165 R. 1173/296 Tornielii-Caetani, 3 abril 1896. El contexto de esta sesión parlamentaria, 1194/300, 5 abril, ASD SP P 54.

${ }^{166}$ La conversación giró también sobre Egipto. R. 1236/317 Tornielli-Caetani, 4 abril 1896, ASD SP P 54.

Hispania, LXV/2, núm. 220 (2005) 643-682 
Tras el encuentro de Guillermo II y Umberto I en Venecia, se habló en Francia del mantenimiento o la disolución de la Triple Alianza. Según Bourgeois, conocer la fecha en que caducaba el acuerdo era fundamental, si quería encauzarse de forma estable las relaciones bilaterales. La opinión pública en cada uno de los países sentiría el alivio de conocer que no había divergencias graves entre sus gobiernos.

Ante la insistencia de Bourgeois, replicó Tornielli que se necesitaban motivos graves para romper los pactos. No los había en el caso de los aliados de Italia. Era imprescindible un giro antes de que expiraran. Si no se conseguía eso, no desaparecería la tensión entre los dos países. Todo lo que se hiciera para destruir malentendidos y evitar noticias que crearan otros iba por el buen camino. Lo más acertado era actuar con claridad. En ese contexto surgió el tema de Tripolitania ${ }^{167}$.

Recordó el embajador una profecía de Thiers: «La République sera conservatrice ou elle ne sera pas». Durante años habían hecho los republicanos proselitismo fuera de sus fronteras. En Italia, esa política se resumía en esta tesis: la pieza clave de la Triple Alianza es la monarquía. Los republicanos italianos serán, por tanto, amigos y aliados de Francia.

La prensa publicó esos días que Italia era el mayor enemigo de Francia. Umberto I era un adversario más encarnizado que Guillermo II. Francia podría llegar a acuerdos y actuar conjuntamente con Alemania en algunas zonas, pero Italia, sometida del todo a Inglaterra, era su enemigo en Europa y África.

Así las cosas, Francia sabría de qué lado debía estar en la guerra de Abisinia. La batalla de Adua había debilitado el ala izquierda de la Triple Alianza. Los franceses deberían pensar que una derrota de los abisinios equivalía a una batalla perdida en la frontera de los Alpes. Francia y Rusia no tenían elección ${ }^{168}$. La guerra en África fue querida sólo por Crispi y los reyes Umberto y Margarita. El país deseaba la evacuación y ahorrarse el coste de la guerra. Di Rudinì, pese a su promesa, nada haría. "La moindre défaite en Abyssinie peut provoquer en Italie une révolution qui anéantira à tout jamais la royauté de la maison de Savoie» 169.

En cuanto a España, la escuadra francesa a comienzos del verano de 1896 visitó los puertos de Coruña, Ferrol y Barcelona y recibió una gran acogida. Los españoles, sobrios en sus expresiones hacia otro país, hablaron de solidaridad entre los dos vecinos. La preocupación por una posible guerra con Estados Unidos les llevaba a creer que la República estaría al lado de España.

El gobierno había recibido una autorización especial, unánimemente votada, para los gastos extraordinarios que los ministerios de Guerra y Marina tu-

\footnotetext{
167 Riservatissimo a conf. 1398/355 Tornielli-Caetani, 16 abril 1896. Sobre la orientación de la prensa francesa, R. 1400/357 22 abril, ASD SP P 54.

168 LILleVOYE, Lucien : «La France et Ménélik», en La Patrie, 16 avril 1896, 1.

169 "La Maison de Savoie. Un article de M. Cipriani sur les événements italiens", en L'Éclair, 16 avril 1896, 1. Los dos artículos como anexos a R 1329/340 Tornielli-Caetani, 16 abril, ASD SP P54.
} 
vieran que afrontar «con motivo de la actual alteración del orden público» en Cuba. Para octubre se pensaba enviar a Cuba otros 40000 soldados, alcanzando la cifra de $170000^{170}$.

En ese clima de patriotismo, el recibimiento que tuvo la flota francesa, instrumento de su política exterior, para algunos debía ser un mensaje al gobierno ${ }^{171}$. Otros lo juzgaban un error, al que no debería dejarse arrastrar ${ }^{172}$. Hanotaux reconoció ante el duque de Mandas que nunca habían sido mejores las relaciones entre los dos países.

Este hecho coincidía con la aproximación entre Roma y París ${ }^{173}$. Marruecos era un asunto excluido en la negociación con Italia. Francia y España defendían el statu quo. Si alguna vez hubiera que pactar con alguien, Francia lo haría sólo con España ${ }^{174}$.

No terminaban de encarrilarse las relaciones franco-italianas como acababan de probar los discursos del presidente del Consejo, el marqués di Rudinì, y del ministro de Exteriores, duque de Sermoneta el 1 de julio en la Cámara. En ellos sostuvieron que los derechos reconocidos por el Bey de Túnez no caducaban al crearse el protectorado francés. El gobierno de Félix Méline estaba dispuesto a hacer concesiones comerciales, si se llegaba a un arreglo en la negociación pendiente sobre Túnez ${ }^{175}$.

Al discutirse el presupuesto de Asuntos Exteriores, los discursos de Nasi, San Giuliano, Damiani, Lucifero y del propio Caetani preocuparon a Billot, el embajador en Roma.

En su encuentro habitual con Tornielli, Gabriel Hanotaux lamentó que se sacaran de nuevo a la luz los problemas de antes y se presentara a Francia como el mayor enemigo de Italia. Aunque el duque de Sermoneta manifestó su amistad hacia Francia, se echaba de menos una réplica al contenido y tono agresivos

\footnotetext{
170 «(Il parlamento) tutto concede che gli si chiegga: uomini e denaro». 436/140 RenzisCaetani, 28 junio 1896. Renzis aseguraba que los gastos mensuales que ocasionaba la guerra en Cuba ascendían a 25 millones de francos, es decir, 300 millones al año. La noticia se la dio el duque de Tetuán. 613, 4 enero, ASD SP P 711896.

${ }^{171}$ Esa fue la interpretación de los diarios republicanos, El Liberal y El País, los dos republicanos. El pueblo «indique surtout à son gouvernement que l'Espagne ne doit pas rester isolée et doit faire, preuve en présence de l'insurrection cubaine, de solidarité européenne!». 104 y 106 L. DescosHanotaux, 27 junio y 2 julio, AAE CP Espagne 928 380-381 y 929, 10-13.

${ }_{172}$ La Correspondencia de España advertía el 24 de junio, que esas expresiones populares, que revelaban una "constante fraternidad" con Francia, podrían molestar o agraviar a Italia, Alemania, Inglaterra, Austria y Rusia, «con las cuales estamos en las más perfectas relaciones». Ante un muy probable «conflicto político» con Estados Unidos, no había que permitir siquiera la apariencia de que se pedía protección a los otros. Las alianzas han de forjarse siempre mediante la negociación. No deben ser fruto de «acelaramientos irreflexivos».

173 «Note du Ministre», 5 juillet, AAE NS Espagne 36 3-6.

174 «Todo, el concurso indirecto, pero eficaz, que Francia pueda damos, nos lo dará, tales como las emisiones colocadas en París y cosas análogas». R. 198 Mandas-Tetuán, 2 de julio, AMAE H 1533.

175301 Mandas-Tetuán, 29 septiembre, AMAE H 1533.
} 
de los otros oradores. Hanotaux no entraba en el derecho de los diputados y de los ministros italianos a formular sus ideas, pero el debate sería recogido en la prensa francesa y dificultaría el propósito de llegar a acuerdos y establecer mejorar el clima entre los dos países. No sería fácil destruir una imagen forjada desde hacía varios años ${ }^{176}$.

Al igual que Cánovas, Onorato Caetani dudaba de la eficacia de las alianzas y creía indispensable concentrar los recursos en la guerra colonial de Abisinia ¿Era el peso que debían soportar potencias de segundo orden? ¿No estaba también Inglaterra, como hemos indicado más arriba, corriendo el riesgo de renunciar a sus derechos para no pagar el precio exigido por su defensa?

La conquista de un espacio colonial o su defensa crearon problemas a todas las naciones europeas. Incrementaban los riesgos. La conveniencia de pactos y la posibilidad de hacerlos en caso de que fuera menester estaban condicionadas por el deseo de paz y por el temor a la guerra, sentimientos a los cuales no podían enfrentarse los gobiernos parlamentarios. Aunque la opinión cerró los ojos ante esa realidad, la labor de la diplomacia fue eficaz. Consiguió lo que pudo, pese a estar lastrada por el quijotesco patriotismo de quienes defendían Cuba y Puerto Rico hasta el último hombre y la última peseta frente a un agresor injusto.

Se llegó en el verano de 1898 al armisticio y se evacuaron Cuba y Puerto Rico el 1 de enero de 1899 sin agotar los recursos militares ni arruinar la hacienda española. Los norteamericanos demostraron valor en la guerra y honor en la victoria. Ni España se hundió ni se produjo esa especie de «juicio de Dios», que esperaban algunos en favor de lo que llamaban «la justicia de nuestra causa». Los comisionados de Estados Unidos defendieron en París con argumentos jurídicos y no a punta de cañón los derechos su país y los de Cuba para el momento en que iniciara su vida como nación soberana. Es verdad que entonces esto no pudo verse así, pero eso no niega que fuera así. Lo que se ha llamado «la perspectiva normalizadora» ${ }^{177}$, fruto del centenario de 1898 , debería ser una catarsis ${ }^{178}$.

\footnotetext{
176 «Delenda est Carthago», en Le Temps, 2 juillet 1896, 1. El debate parlamentario era una estrategia de oposición política interna. El diario, que tenía una buena relación con Hanotaux, era una excepción. En los días sucesivos afirmó la posibilidad y conveniencia de una relación amistosa con Italia. R. 2276/565 Tornielli-Caetani, 2 julio 1896, ASD SP P 54 y DDI III/I (Roma 1963) pp. $85-86$ y 23441584,8 agosto, ASD SP P 54.

177 ElIZALDE, María Dolores: «El 98 desde una perspectiva normalizadora. Reflexión historiográfica de un centenario», en Hispania (Madrid) 208 (2001) pp. 707-736.

178 La sociedad española necesita liberarse de algunos de los fantasmas que la hacen sentirse maltratada. Basta ver algunas de las reacciones como las que se produjeron en la segunda quinceria de noviembre del 2001, en el encuentro de Barcelona sobre el futuro de Gibraltar y en la primavera del 2003 al estallar la guerra contra Irak.
} 